\title{
əorigin of Strong Winds in an Explosive Mediterranean Extratropical Cyclone
}

\author{
MIHAELA BRÂNCUŞ \\ Department of Earth and Atmospheric Physics Faculty of Physics, University of Bucharest, and National Meteorological \\ Administration, Bucharest, Romania \\ DAVID M. SCHULTZ \\ Centre for Atmospheric Science, School of Earth and Environmental Sciences, and Centre for Crisis Studies and Mitigation, \\ University of Manchester, Manchester, United Kingdom \\ BOGDAN ANTONESCU \\ Department of Earth and Atmospheric Physics Faculty of Physics, University of Bucharest, Bucharest, and \\ National Institute of $R \& D$ for Optoelectronics, Măgurele, Romania

\section{CHRISTOPHER DEARDEN} \\ Centre for Environmental Modelling and Computation, School of Earth and Environment, University of Leeds, \\ Leeds, United Kingdom \\ SABINA ŞTEFAN \\ Department of Earth and Atmospheric Physics Faculty of Physics, University of Bucharest, Bucharest, Romania
}

(Manuscript received 12 January 2019, in final form 26 July 2019)

\begin{abstract}
During 2-3 December 2012, the Black Sea and east coast of Romania were affected by a rapidly deepening Mediterranean cyclone. The cyclone developed a bent-back front along which short-lived $(2-4 \mathrm{~h})$ strong winds up to $38 \mathrm{~m} \mathrm{~s}^{-1}$ were recorded equatorward of the cyclone center. A mesoscale model simulation was used to analyze the evolution of the wind field, to investigate the physical processes that were responsible for the strong winds and their acceleration, and to investigate the relative importance of the stability of the boundary layer to those strong winds. The origin of the air in the wind maximum equatorward of the cyclone center was twofold. The first was associated with a sting jet, a descending airstream from the midlevels of the cloud head and the lower part of the cyclonic branch of the warm conveyor belt. The sting jet started to descend west of the cyclone center, ending at the frontolytic tip of the bent-back front. The second was a low-level airstream associated with the cold conveyor belt that originated northeast of the cyclone center and traveled below $900 \mathrm{hPa}$ along the cold side of the bent-back front, ending behind the cold front. Both airstreams were accelerated by the along-flow pressure gradient force, with the largest accelerations acting on the sting-jet air before entering into the nearsurface strong-wind area. The sensible heat fluxes destabilized the boundary layer to near-neutral conditions south of the cyclone center, facilitating downward mixing and allowing the descending air to reach the surface. Mesoscale instabilities appeared to be unimportant in the sting-jet formation.
\end{abstract}

D Denotes content that is immediately available upon publication as open access.

Corresponding author: Mihaela Brâncuş, mihaela.brancus@ yahoo.com

\section{Introduction}

One of the threats of extratropical cyclones is the strong nonconvective surface winds associated with them (e.g., Hewson and Neu 2015). These strong surface winds can 
occur in at least three locations around the cyclone: within the warm sector, within the cold conveyor belt, and as a result of the sting jet. Strong surface winds can also occur behind the cold front in association with a tropopause fold (e.g., Parton et al. 2010; Knox et al. 2011). In the warm sector, strong winds occur as air is accelerated poleward toward the cyclone center and ascends in the synoptic-scale warm conveyor belt (e.g., Carlson 1980; Harrold 1973; Browning 1990). The cold conveyor belt is also a synoptic-scale airstream, generally situated below $800 \mathrm{hPa}$, which originates northeast of the cyclone center and wraps cyclonically around the cyclone center (e.g., Carlson 1980; Schultz 2001).

Although both the warm and cold conveyor belts are general features of extratropical cyclones, some cyclones also produce sting jets. The sting jet is a transient feature of an intense Shapiro-Keyser extratropical cyclone (Shapiro and Keyser 1990) that forms in the midlevels of the cloud head, poleward and west of the cyclone center and descends, while accelerating, to the end of the bent-back front (Browning 2004; Schultz and Browning 2017; Clark and Gray 2018). With a footprint smaller than that of the warm or cold conveyor belts, the sting jet is a mesoscale phenomenon (i.e., several hundred kilometers or less in the alongfront direction and tens of $\mathrm{km}$ in the across-front direction). Schultz and Sienkiewicz (2013) showed that the mesoscale dimension of the sting jet is related to the mesoscale dimension of the associated frontolytic circulation at the end of the bent-back front. The vertical velocities associated with this circulation are of order $10 \mathrm{~cm} \mathrm{~s}^{-1}$ and are sufficient to realize the descent of air from the midtroposphere in several hours.

The descent and acceleration of the sting-jet air have been suggested to be caused by evaporative cooling (Browning 2004; Clark et al. 2005), the release of conditional symmetric instability (Parton et al. 2009; Gray et al. 2011; Martínez-Alvarado et al. 2011), and the secondary circulation associated with Petterssen frontogenesis (Schultz and Sienkiewicz 2013; Slater et al. 2015, 2017). In contrast, some studies have found no evidence for the acceleration of the winds in the sting jet to be caused by evaporative cooling (Smart and Browning 2014; Baker et al. 2014) or the release of conditional symmetric instability (Smart and Browning 2014; Coronel et al. 2016).

To date, sting jets have been identified in extratropical cyclones over the North Atlantic and Europe using observational (e.g., Parton et al. 2009; MartínezAlvarado et al. 2014; Vaughan et al. 2015) and reanalysis data (e.g., Hewson and Neu 2015). Sting jets may occur elsewhere, as well. For example, the present study considers a case of explosive Mediterranean cyclogenesis with a possible sting jet on 2-3 December 2012. The cyclone developed a bent-back front and strong winds equatorward of the cyclone center, affecting the Black Sea coast of Romania. Intense winds were recorded (up to $38 \mathrm{~m} \mathrm{~s}^{-1}$ ) that had a strong societal and economic impact. Specifically, all seaports were closed, the sea withdrew about $50 \mathrm{~m}$ from the shore due to strong westerly winds, more than 105 localities were left without power, 28 localities lost their water supply, 22 school buildings and 348 houses were damaged, dozens of trees were uprooted, and some trees fell onto cars (Observator de Constanţa 2012). Also, parts of the wind farms from Constanţa county were damaged by the strong winds, and Unit 1 of the Cernavodă nuclear power plant was shut down at 0300 UTC 3 December (LT = UTC $+2 \mathrm{~h}$ ) for "technological protection of the reactor because of weather conditions" (Pirvoiu 2012; Nuclearelectrica 2012). No fatalities were recorded.

The question that is the focus of this article is: "What is the cause of these strong winds?" Cold conveyor belt? A sting jet? Both? In this article, we investigate the structure, evolution, and physical processes involved in the formation of the wind maximum equatorward of this cyclone. In addition to observations (e.g., satellite images, surface weather station data, S-band Doppler radar products), an analysis of the cyclone based on a high-resolution model was used to provide a complementary perspective of the event.

The article continues with an overview of the cyclone evolution based on observations in section 2 . The setup of the numerical model used for the simulation is presented in section 3 . In section 4 , the evolution and the structure of the wind field near the surface during the period when the winds were strongest is described. Section 5 presents how Petterssen frontogenesis was used to investigate whether the generation of the intense winds is a response to mesoscale dynamics. In section 6 , backward air-parcel trajectories were calculated to establish the path followed by the airstreams associated with the wind maxima. The mechanisms that accelerated the airstreams are analyzed in section 7. The role played by mesoscale instabilities during the lifetime of the strong winds is investigated in section 8. Finally, section 9 contains a summary of the most important findings of this article.

\section{Cyclone overview}

The cyclone analyzed in this article resulted from the interaction of two cyclone centers in confluent upperlevel flow. The first one (L1) formed in the central basin 


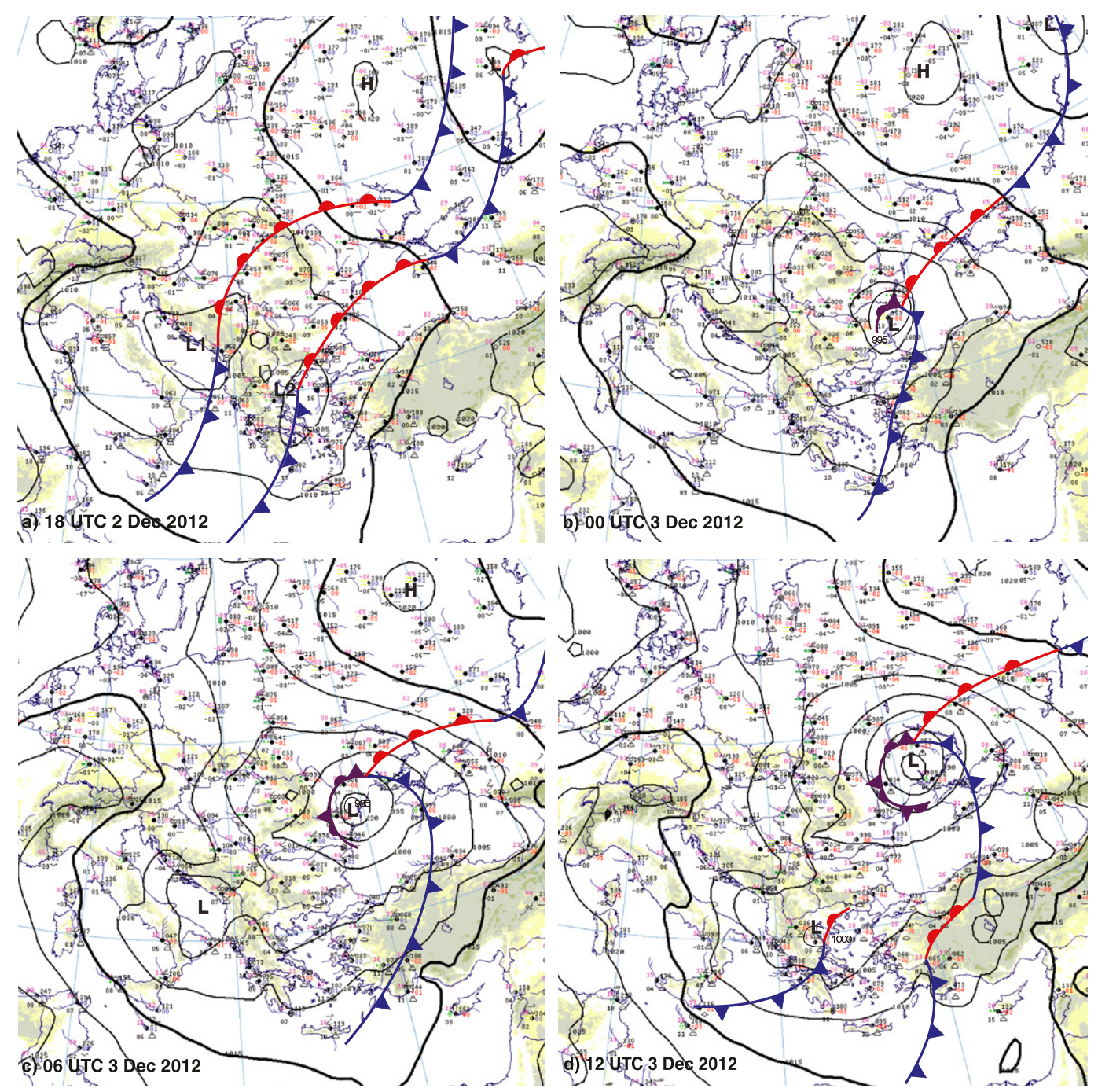

FIG. 1. Surface analysis. Mean sea level pressure contoured every $5 \mathrm{hPa}$, station plots, and front analysis at (a) 1800 UTC 2 Dec, (b) 0000, (c) 0600, and (d) 1200 UTC 3 Dec 2012 (courtesy of Romanian National Meteorological Administration).

of the Mediterranean Sea and moved east-northeast over the Adriatic Sea toward the Black Sea. The second one (L2) moved from the southern basin of the Mediterranean Sea on a northeastward path (Fig. 1a). After 1800 UTC 2 December, the two cyclones merged, and the single cyclone center began deepening rapidly, reaching its minimum central pressure over the Black Sea at 0600 UTC 3 December (Figs. 1b,c,d). The central pressure of the cyclone dropped more than $20 \mathrm{hPa}$ in $12 \mathrm{~h}$, from $1005 \mathrm{hPa}$ at 1800 UTC 2 December to less than $985 \mathrm{hPa}$ at 0600 UTC 3 December. Thus, the cyclone satisfied the criterion to be classified as an atmospheric bomb by deepening 1.5 Bergerons (Sanders and Gyakum 1980) (in this case, $\sin \phi=45^{\circ} \mathrm{N}$, so 1 Bergeron at $45^{\circ} \mathrm{N}$ equals $19.6 \mathrm{hPa}$ in $24 \mathrm{~h}$ ).
At $500 \mathrm{hPa}$, a short-wave trough associated with the surface cyclone was embedded in a large-scale trough extending across Europe southward to the Mediterranean Sea (Fig. 2a). Between 0000-1200 UTC 3 December, the short-wave trough, located over the Adriatic Sea at 1800 UTC, moved northeastward and a closed circulation formed (Figs. 2b-d). In less than $12 \mathrm{~h}$, the cyclone underwent the frontal-fracture stage and the T-bone stage of the Shapiro-Keyser conceptual model, when the cold front and the warm front became nearly perpendicular and the bent-back front developed west of the warm front (Figs. 1a-c). The well-developed bent-back front started to wrap around and encircled the cyclone center twice by 1200 UTC 3 December (Fig. 1d). 

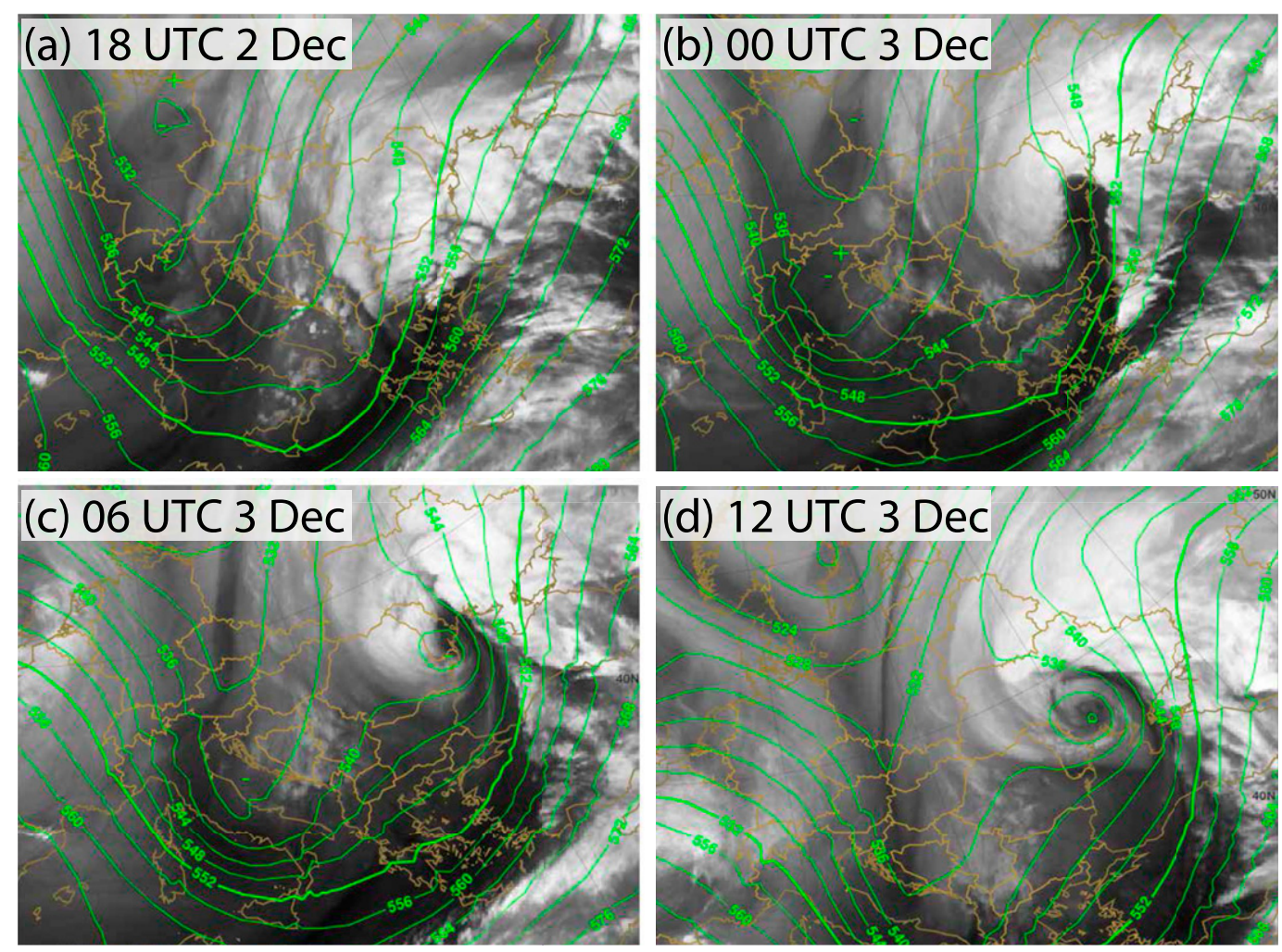

FIG. 2. Meteosat-9 water vapor imagery and geopotential height at $500 \mathrm{hPa}$ (green lines, every 4 dam) analysis from ECMWF at (a) 1800 UTC 2 Dec, (b) 0000, (c) 0600, and (d) 1200 UTC 3 Dec 2012 (courtesy of EUMETSAT). The domain in (a)-(c) is different from the domain in (d) so that both the frontal systems and the upper-level structure are centered.

The bent-back front brought heavy rainfall to eastern Romania, snow in the Carpathian Mountains, and damaging winds to southeastern Romania. Strong wind gusts were recorded over land (e.g., up to $36 \mathrm{~m} \mathrm{~s}^{-1}$ at Medgidia) and over sea ( $38 \mathrm{~m} \mathrm{~s}^{-1}$ at Gloria Oil Platform station) for a period of about 4-6h (Fig. 3a). As the cyclone deepened and traveled northward, the weather stations in southeastern Romania recorded the evolution of the pressure. The minimum pressure was recorded between 0300 and 0600 UTC, starting with southern stations (Fig. 3b). For example, Sulina recorded $980.2 \mathrm{hPa}$ at $0600 \mathrm{UTC}$, the lowest pressure value ever recorded at this weather station.

Due to the rapid intensification of the wind, nowcasting yellow and orange code warnings were issued by the Romanian National Meteorological Administration Constanţa Regional Weather Forecasting Service. This case could have been the subject of a red-code nowcasting warning because the threshold for a redcode warning is a wind speed greater than $30 \mathrm{~m} \mathrm{~s}^{-1}$. The color codes are set according to the severity of the phenomena, from yellow to red, respectively; the thresholds of the phenomena are calibrated appropriately to each country's climatology (Stepek et al. 2012). The nowcasting warnings complement the longer-range warnings issued for the next $24-48 \mathrm{~h}$ that are part of the European METEOALARM system (www.meteoalarm.eu; Meteoalarm 2013). These warnings are issued for dangerous weather phenomena (e.g., wind, rain, severe thunderstorm, snow, blizzard, fog) that have not been warned on or have been warned on but could become more dangerous than expected within the next $6 \mathrm{~h}$. All these warnings are meant to inform the public about the possible occurrence of highimpact weather.

The Medgidia S-band Doppler radar, situated in southeastern Romania recorded the passage of the bentback front (Fig. 4, bottom). Between 0236 and 0611 UTC 3 December, the radar velocity-azimuth display (VAD) wind-profiler product showed wind speeds greater than $35 \mathrm{~m} \mathrm{~s}^{-1}$ at a height of about $3 \mathrm{~km}$, with a peak between 0300 and 0400 UTC (Fig. 4, top). At the beginning of the event, the "ND" notation (for "no detection") meant that precipitation particles were not strong enough to obtain a velocity measurement. The high values of the root-mean-square error (RMSE) 


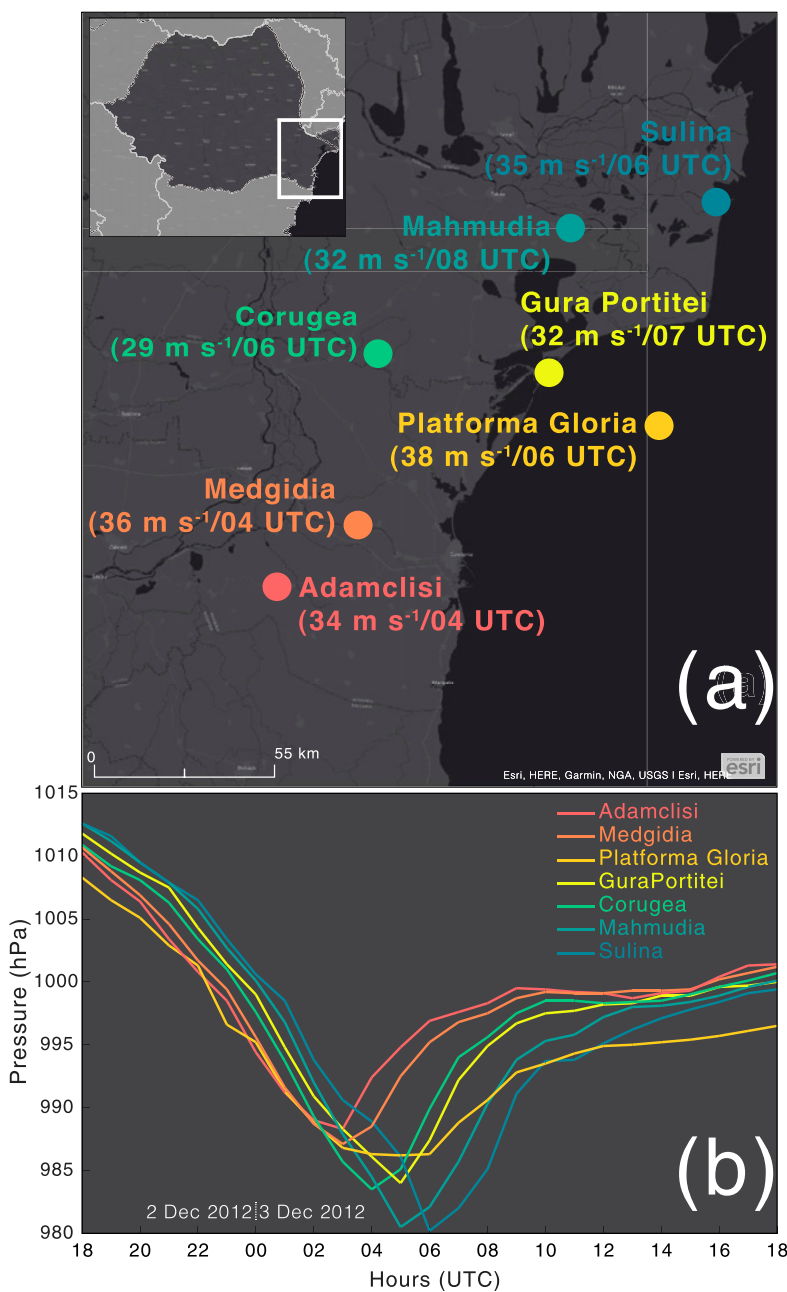

FIG. 3. (a) The maximum wind speed as recorded by some of the weather stations from the network of the Romanian National Meteorological Administration between 0400 and 0800 UTC 3 Dec 2012. The weather station names are colored based on their geographic position from south (red) to north (blue). (b) The evolution of sea level pressure as recorded by the weather stations in (a) between 1800 UTC 2 Dec and 1800 UTC 3 Dec.

were likely due to ground clutter or turbulence, but reliable data (i.e., green color barbs in Fig. 4, top) were present through the entire period of the event. The base velocity product at $0.5^{\circ}$ elevation (Fig. 4 , middle) showed that the region with the strongest wind $\left(>26 \mathrm{~m} \mathrm{~s}^{-1}\right)$ had a mesoscale dimension, less than $100 \mathrm{~km}$ wide. Values larger than $33 \mathrm{~m} \mathrm{~s}^{-1}$ were recorded at 0300 UTC near Cernavodă city at the time when the nuclear reactor was shut down.

These observations indicated the rapid evolution of the strong winds in association with this deep ShapiroKeyser cyclone. But, the sparse weather-station network could not capture the scale of these severe winds within the cyclone nor provide adequate data to understand their origin. Therefore, a mesoscale model simulation was used to explain the physical processes involved in the structure and evolution of the wind field.

\section{Model setup}

The cyclone case was simulated using the Advanced Research Weather Research and Forecasting (WRF) Model, version 3.6.1 (Skamarock et al. 2008) a compressible, nonhydrostatic, three-dimensional mesoscale model. The European Centre for Medium-Range Weather Forecasts (ECMWF) analysis at $0.25^{\circ}$ latitudelongitude was used to initialize the model and to provide lateral boundary conditions every $6 \mathrm{~h}$. The simulation used a single $419 \times 419$ gridpoint domain with $9-\mathrm{km}$ horizontal grid spacing and 100 vertical levels; the vertical spacing varied from 100 to $215 \mathrm{~m}$ in the lower and midtroposphere. The model was run with the Thompson microphysics scheme (Thompson et al. 2008), the Kain-Fritsch cumulus parameterization scheme (Kain and Fritsch 1990; Kain 2004), Yonsei University planetary boundary layer scheme (Hong et al. 2006), the unified Noah land surface model (Chen and Dudhia 2001; Ek et al. 2003), the shortwave radiation scheme by Dudhia (1989), and the Rapid Radiative Transfer Model (RRTM) longwave radiation scheme (Mlawer et al. 1997). The simulation was initialized at 0000 UTC 2 December 2012 and run for $36 \mathrm{~h}$. The model output was hourly except for 0000 0900 UTC 3 December when output was every $15 \mathrm{~min}$ to capture the detail of the structure and evolution of the wind field during this time.

\section{Evolution of the wind field equatorward of the cyclone center}

For approximately $7 \mathrm{~h}$ starting at 0000 UTC 3 December, the 925-hPa wind field equatorward of the cyclone center evolved remarkably fast. At 0030 UTC, a wide area of strong winds was present in front of and within the cold front (Fig. 5a). West of this area at about $28^{\circ} \mathrm{E}$, a footprint of strong near-surface winds exceeding $35 \mathrm{~m} \mathrm{~s}^{-1}$ began to appear. Within an hour, these winds intensified and the footprint enlarged. The tear-shaped wind maximum labeled $\mathrm{W} 1$ (speeds $>45 \mathrm{~m} \mathrm{~s}^{-1}$ ) was situated south of and close to the cyclone center in an area where the isentropes were spreading apart (Fig. 5b). The tear-shaped structure of W1 resembled the sting-jet structure depicted in Fig. 6 from Schultz and Sienkiewicz (2013), suggesting the possibility that this wind maximum associated with this Mediterranean cyclone was in part due to a sting jet. West of W1, another maximum W2 formed at 0230 UTC, 


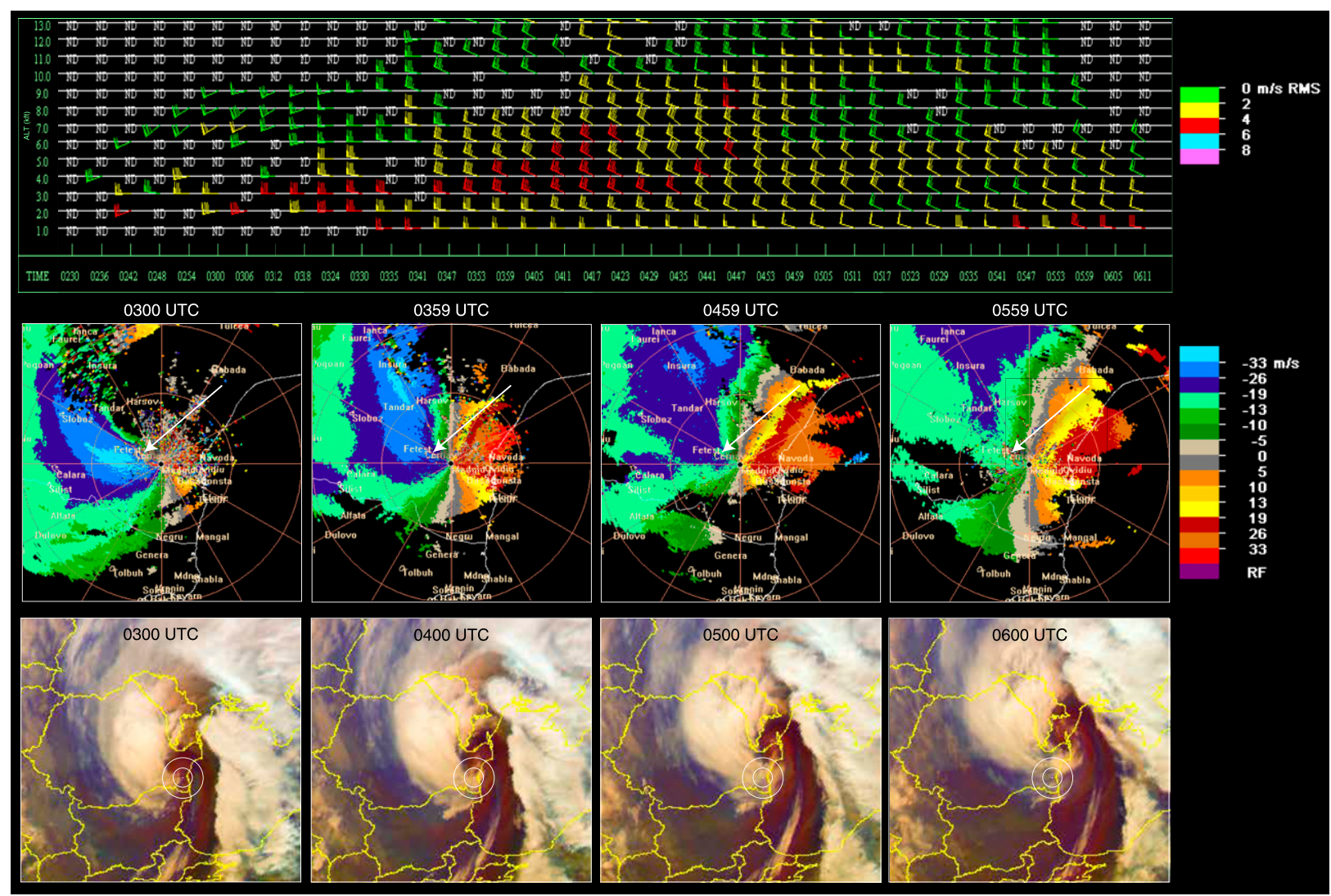

FIG. 4. Products of Medgidia S-band Doppler radar are provided through the courtesy and are the copyright of the Romanian National Meteorological Administration (position of the city is highlighted by the white dot in satellite images): (top) VAD wind profiler 02300611 UTC 3 Dec. The barbs are colored according to the RMSE (root-mean-square error) scale on the right (pennant, barbs, and halfbarbs denote wind speeds of 25, 5, and $2.5 \mathrm{~m} \mathrm{~s}^{-1}$, respectively). Except for the lower-right winds (0511-0611 UTC), all winds are over $25 \mathrm{~m} \mathrm{~s}^{-1}$; (middle) base velocity $0.5^{\circ}$ elevation for $0300,0359,0459$, and 0559 UTC 3 Dec ( $\mathrm{m} \mathrm{s}^{-1}$ shaded according to the scale). The first circle from radar denotes a 50-km range, and the second one a 100-km range. The white arrow indicates the location of Cernavodă city. (bottom) Meteosat Second Generation airmass RGB satellite images for 0300, 0400, 0500, and 0600 UTC 3 Dec 2012. Cold air mass (low tropopause) is depicted bluish, warm air mass (high tropopause) yellow-greenish, and dry descending stratospheric air appears reddish. The white-reddish clouds represent the midlevel clouds while high clouds appear white-gray. The white circles represent the radar base velocity circles.

but with a smaller area and a reduced intensity compared to W1 (Fig. 5c). After the formation of W2, the footprint of $\mathrm{W} 1$ and its maximum speed both decreased (Fig. 5d). W1 had values below $40 \mathrm{~m} \mathrm{~s}^{-1}$, and W2 had values less than $45 \mathrm{~m} \mathrm{~s}^{-1}$, indicating that the maximum severity of the wind might have already occurred and the threat from strong winds was over (Fig. 5d). Instead, at 0415 UTC, a new maximum of winds W3 formed, separate from W1 and W2. As evidence that $\mathrm{W} 3$ was a new maximum, $\mathrm{W} 2$ had $\theta$ between $288 \mathrm{~K}$ on the leading part and $286 \mathrm{~K}$ on the rear part. In contrast, W3 had $\theta$ of $287-289 \mathrm{~K}$. Also, during the next hour (0315-0415 UTC), the footprints of W1 and $\mathrm{W} 2$ reduced in size, weakened, and moved east. In contrast, the footprint of W3 elongated and enlarged, and the speed increased to $40-45 \mathrm{~m} \mathrm{~s}^{-1}$ (not shown).
Also, forward trajectories showed that W2 does not become the leading edge of $\mathrm{W} 3$ at a later time (not shown). After 0315 UTC, the W1-W2 maximum and W3 merged and the strong wind speed was maintained for almost another $3 \mathrm{~h}$ until 0700 UTC (Figs. 5e,f). After this time, the strongest winds remained southeast of the cyclone center, but were weaker. Both W1 and W2, as well as W3, occurred before the cyclone reached its minimum central pressure of $972 \mathrm{hPa}$, which was attained at 0700 UTC.

The 700-hPa relative humidity field was used to determine the position of wind maxima relative to the cyclone's lower-tropospheric cloud field during the analyzed period. W1 was situated in an area with low relative humidity, on the warm side and at the tip of the cloud head (Fig. 6a), similar to the positions of other 

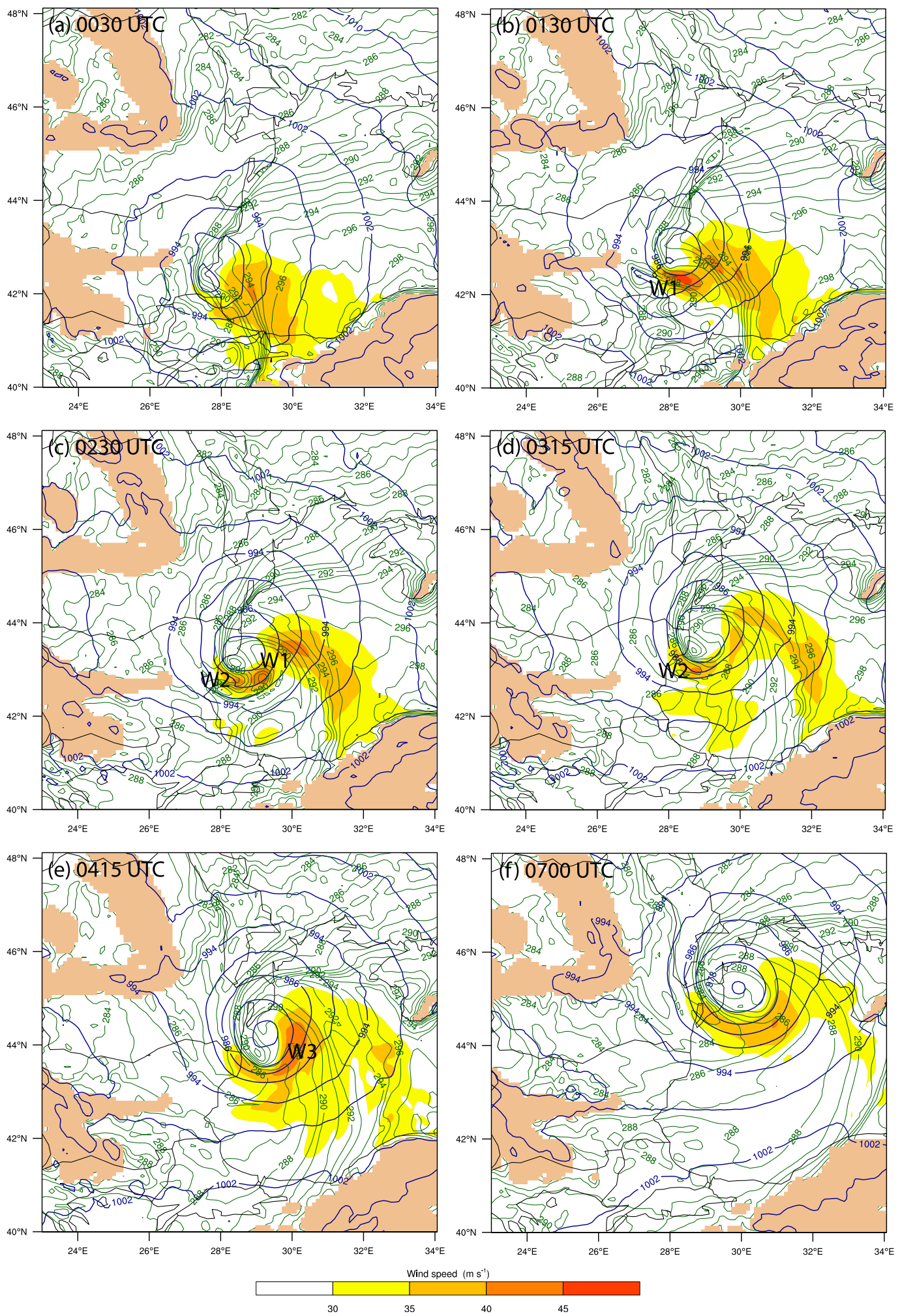

FIG. 5. Sea level pressure (blue lines every $4 \mathrm{hPa}$ ), potential temperature (dark green lines every $1 \mathrm{~K}$ ), and horizontal wind speed at $925 \mathrm{hPa}$ (shaded above $30 \mathrm{~m} \mathrm{~s}^{-1}$ according to the scale): (a) 0030, (b) 0130, (c) 0230, (d) 0315, (e) 0415, and (f) 0700 UTC 3 Dec 2012. W1, W2, and W3 represent the near-surface wind maxima occurring equatorward of the cyclone center at 0130, 0230, and 0415 UTC, respectively. The black lines represent the political boundaries. The brown shading represents areas in which the $925-\mathrm{hPa}$ surface is below ground. 

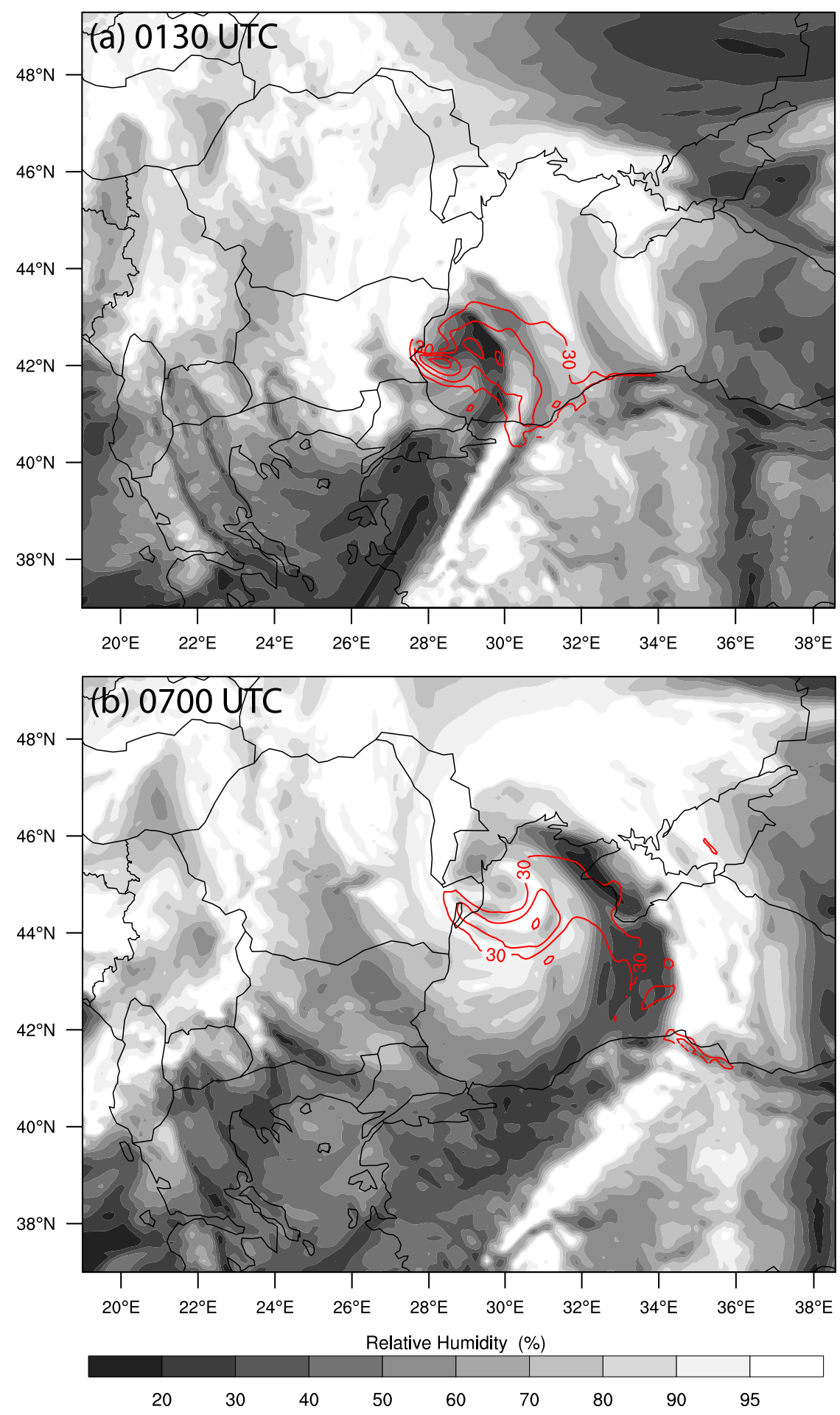

FIG. 6. Relative humidity at $700 \mathrm{hPa}$ (shaded according to the scale) and horizontal wind speed at $925 \mathrm{hPa}$ (solid red lines contoured from 30 to $50 \mathrm{~m} \mathrm{~s}^{-1}$ every $5 \mathrm{~m} \mathrm{~s}^{-1}$ ) at (a) 0130 and (b) 0700 UTC 3 Dec. 
observed and modeled sting jets (e.g., Browning 2004; Baker 2009; Slater et al. 2017; Volonté et al. 2018). Later, when the bent-back front wrapped around the cyclone center, the strongest winds were located in a region with relative humidity higher than $80 \%-90 \%$ (Fig. 6b). In the next sections, we focus on understanding the physical processes that contributed to the evolution of the wind field.

\section{Petterssen frontogenesis}

To establish what mechanisms are responsible for the generation of strong winds and whether this cyclone produced a sting jet, frontal processes are investigated using Petterssen frontogenesis. Petterssen (1936) frontogenesis has been used as a diagnostic tool to indicate that the indirect circulation at the frontolytic end of the bent-back front was closely related to the descent of the air in the sting jet (Schultz and Sienkiewicz 2013; Slater et al. 2015, 2017). Petterssen (1936) defined frontogenesis $F$ as the Lagrangian rate of change of the magnitude of the horizontal potential temperature $(\theta)$ gradient due to the horizontal wind $\left(\mathbf{V}_{h}=u \mathbf{i}+v \mathbf{j}\right)$ :

$$
F=\frac{d}{d t}\left|\nabla_{2} \theta\right|,
$$

where $\nabla_{2}=\mathbf{i}(\partial / \partial x)+\mathbf{j}(\partial / \partial y)$. Petterssen (1936) showed that, if potential temperature is conserved, then $F$ could be rewritten in terms of the deformation and divergence as

$$
F=\frac{1}{2}\left|\nabla_{2} \theta\right|\left(E \cos 2 \beta-\nabla_{2} \cdot \mathbf{V}_{h}\right),
$$

where $E$ is the resultant deformation and $\beta$ is the local angle between an isentrope and the axis of dilatation.

Confluence and convergence acting on a horizontal temperature gradient will increase the gradient and result in frontogenesis, whereas diffluence and divergence will decrease the gradient and result in negative frontogenesis (i.e., frontolysis). Diffluence at the end of the bent-back front associated with Petterssen frontolysis is characteristic of a Shapiro-Keyser cyclone (Takayabu 1986; Schär and Wernli 1993; Schultz et al. 1998). Frontolysis is also associated with an indirect circulation: warm air sinking and cold air rising. At the frontolytic region at the end of the bent-back front, the typical presence of cold advection shifts the indirect circulation so that the region of descent occurs within the frontal zone and the region of frontolysis, facilitating the downward transport of high-momentum air.

In this Mediterranean cyclone, the winds that might have been associated with a sting jet were located at the tip of the cloud head (Fig. 6a). Thus, we examined frontogenesis and frontolysis along the bent-back front at $925 \mathrm{hPa}$. We chose this level because frontal structures are better defined at this level than at the surface, where surface parameterizations in the model create a noisier field, and compared to $850 \mathrm{hPa}$, where the fronts are weaker. During 0130-0230 UTC, the warm front north of the surface cyclone center exhibited strong frontogenesis (Figs. 7a,b). In contrast, at the tip of the cloud head, W1 and W2 were extending into a region where the isentropes became diffluent, decreasing the horizontal temperature gradient, and resulting in a maximum of frontolysis (Figs. 7a,b). This region of frontolysis weakened by 0415 UTC (Fig. 7c). Hence, Petterssen frontogenesis, with frontolysis at the end of the bent-back front and its associated secondary circulation, appears related to the locations of $\mathrm{W} 1$ and W2 and possibly provides a physical mechanism for bringing the strong winds down to the surface along a mesoscale swath.

To illustrate the vertical structure of the wind maxima, Petterssen frontogenesis, vertical velocity associated with the frontal structures, and how they are related, three cross sections were made along the bent-back front. Also, to illustrate and to contrast the alongfront and the across-front circulations, another three cross sections perpendicular to each wind maximum were made (locations of cross sections in Figs. $7 \mathrm{a}-\mathrm{c}$ ).

Cross section $\mathrm{AA}^{\prime}$ was taken south of the cyclone center along the region of frontolysis and along the core of W1 at 0130 UTC (Fig. 8a). A large and continuous wind maximum extended from the surface to the upper troposphere, with speed increasing with height. Two local maxima in wind speed were observed within this larger maximum. The first maximum $\mathrm{W} 1$ was located at around $2 \mathrm{~km}$ height in an area dominated by strong descent (i.e., 8.0 $\mathrm{Pa} \mathrm{s}^{-1}$ in Fig. 8a), with frontolysis extending below the wind maximum. Although the W1 core in the cross section was not associated with frontogenesis or frontolysis, frontolysis was present when $\mathrm{W} 1$ formed and descended (not shown). The total descent in the across-front direction in W1 was narrow, strong, and of comparable scale to the frontogenesis, suggesting these vertical circulations were frontal circulations in which the across-front circulations were responding to the region of frontolysis at the end of the bent-back front (Fig. 8b).

Another local maximum in wind speed occurred above $\mathrm{W} 1$, around 3-6 km height in an area with weak baroclinicity, negligible frontogenesis, and weak downward vertical velocities (Fig. 8a). This wind maximum seemed to be a region of midtropospheric westerly flow.

Behind and upstream of W1, the isentropes sloped downward to the southeast, consistent with the bent-back 

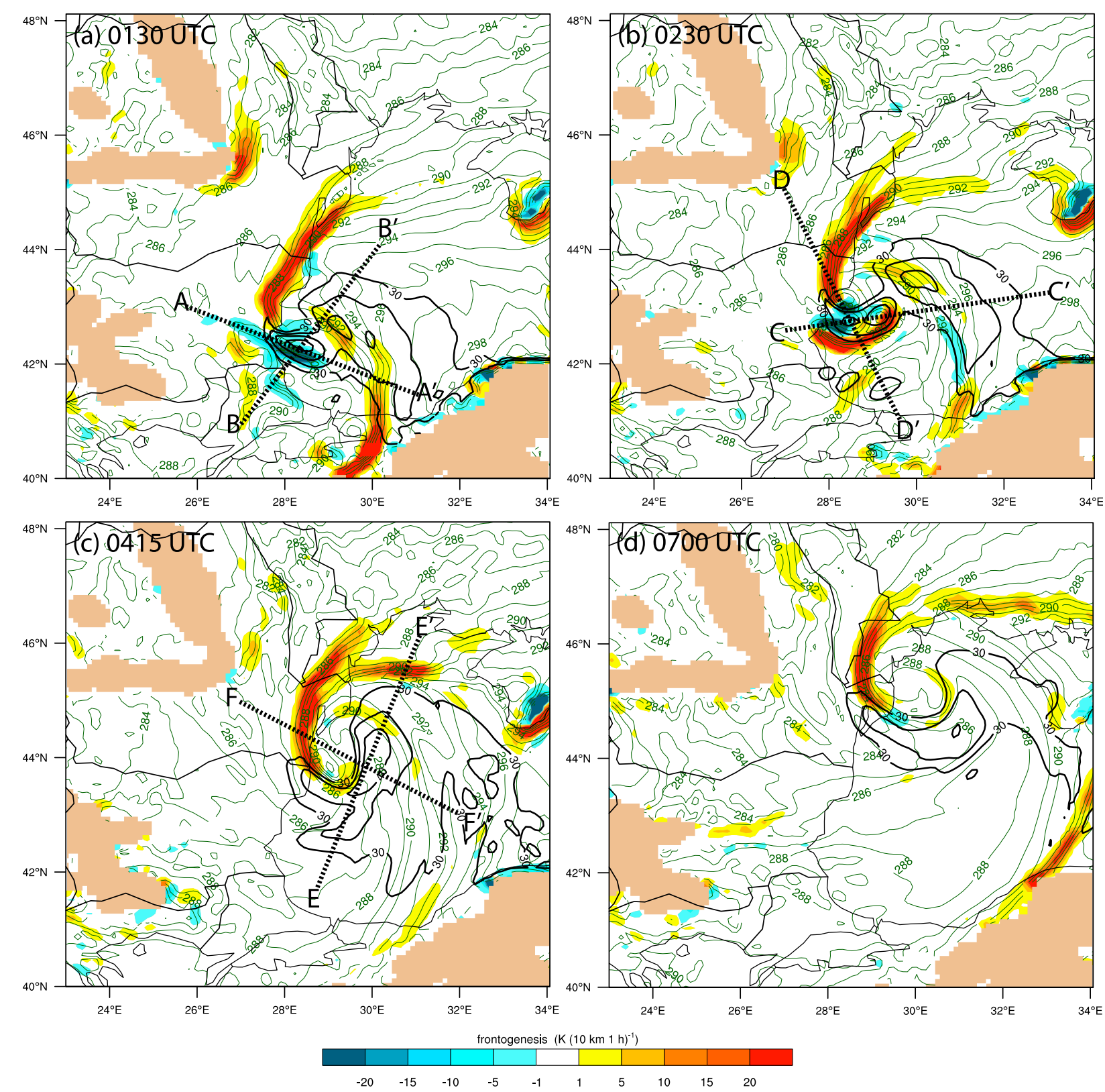

FIG. 7. The $925-\mathrm{hPa}$ Petterssen frontogenesis $\left[\mathrm{K}(10 \mathrm{~km})^{-1}(1 \mathrm{~h})^{-1}\right.$, shaded according to the scale], potential temperature (dark green lines every $1 \mathrm{~K}$ ), and horizontal wind speed (black lines $>30 \mathrm{~m} \mathrm{~s}^{-1}$ ): (a) 0130, (b) 0230, (c) 0315, and (d) 0700 UTC 3 Dec. The dashed lines in (a)-(c) represent the position of the cross section shown in Fig. 8. The brown shading represents areas in which the 925-hPa surface is below ground.

front (Fig. 8a). The region where the isentropes were almost horizontal (below $2 \mathrm{~km}$ height about $28.6^{\circ}-$ $30.0^{\circ} \mathrm{E}$ in $\mathrm{AA}^{\prime}$ ) marked the small distance between the cloud head and the cold front.

Cross section $\mathrm{CC}^{\prime}$ was taken south of the cyclone center along the frontolysis maxima and along W1 and W2 at 0230 UTC (Fig. 8c). By this time, W1 was found at a lower altitude (around $1.5 \mathrm{~km}$ in height) than at 0130 UTC and had wind speeds faster than
$50 \mathrm{~m} \mathrm{~s}^{-1}$. The second wind maximum $\mathrm{W} 2$ was positioned above the surface, in an area with frontolysis and strong descent. The cross section $\mathrm{DD}^{\prime}$ showed that the total descent in the across-front direction was extending in the W2 area (Fig. 8d). The downward-folding isentropes were associated with both W1 and W2 (Fig. 8c). W1 was characterized by weak vertical stability and was separated from W2 by a strong statically stable layer. That statically stable layer was probably generated by 

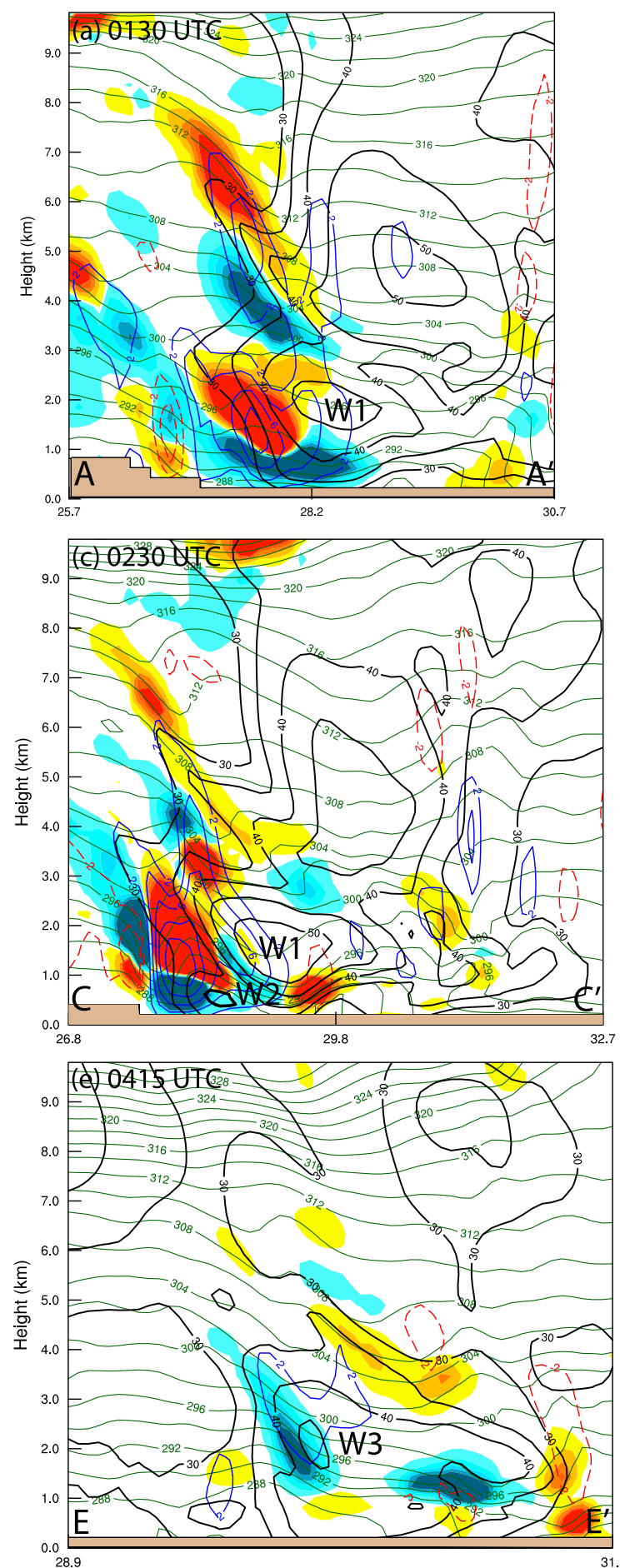
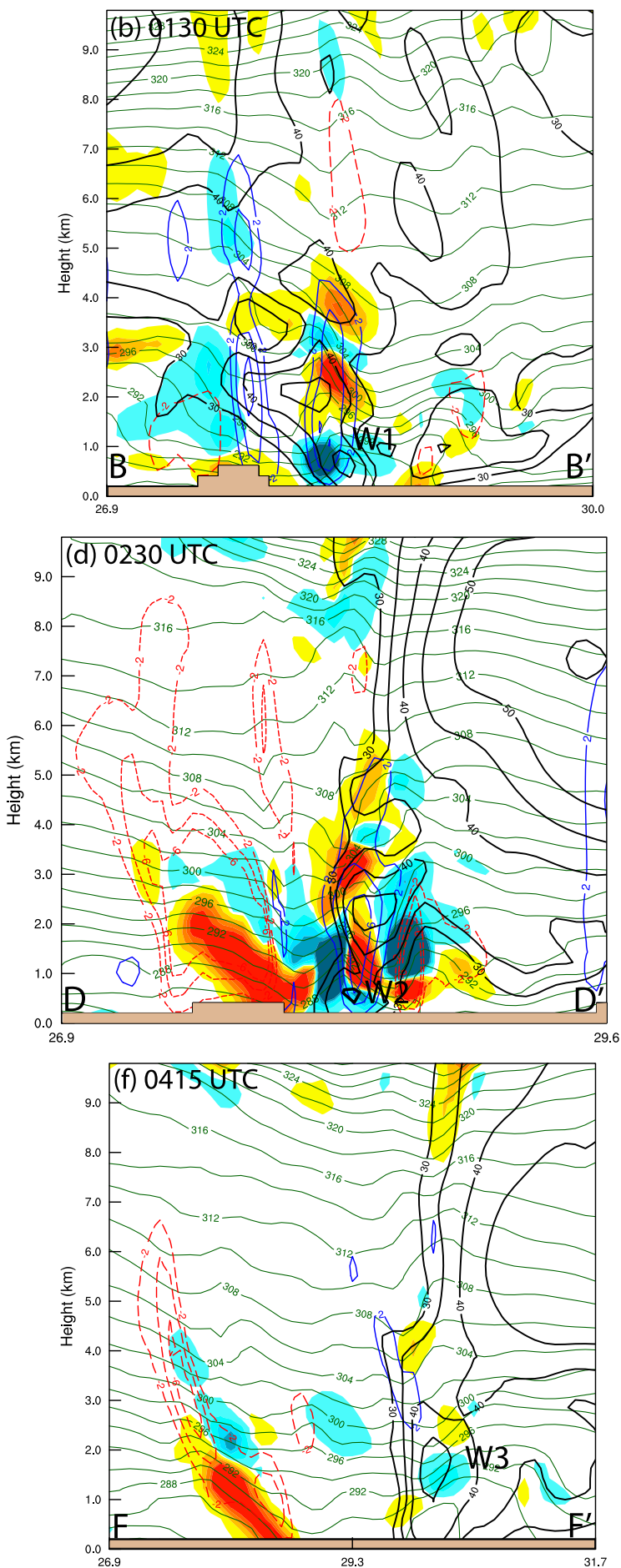

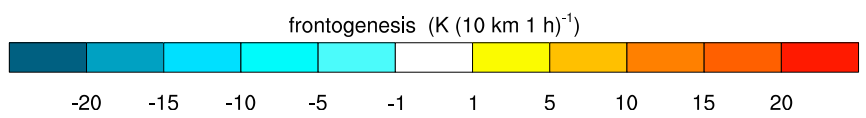

FIG. 8. Vertical cross sections taken (a),(c),(e) along- and (b),(d),(f) across-front, $\mathrm{AA}^{\prime}$ and $\mathrm{BB}^{\prime}$, respectively, at $0130 \mathrm{UTC}$; CC' and DD', respectively, at $0230 \mathrm{UTC}$; and $\mathrm{EE}^{\prime}$ and $\mathrm{FF}^{\prime}$, respectively, at $0415 \mathrm{UTC}$ (the positions of cross sections are illustrated in Fig. 7). Vertical axis is height $(\mathrm{km})$ and horizontal axis represents longitude coordinates. Petterssen frontogenesis $\left[\mathrm{K}(10 \mathrm{~km})^{-1}(1 \mathrm{~h})^{-1}\right.$ shaded according to the scale], potential temperature (dark green lines contoured every $2 \mathrm{~K}$ ), horizontal wind speed (solid black lines contoured from 30 to $50 \mathrm{~m} \mathrm{~s}^{-1}$ every $5 \mathrm{~m} \mathrm{~s}^{-1}$ ), and omega (dashed red lines represent ascent contoured from -10.0 to $-2.0 \mathrm{~Pa} \mathrm{~s}^{-1}$ every $2.0 \mathrm{~Pa} \mathrm{~s}^{-1}$; solid blue lines represent descent contoured from 2.0 to $10.0 \mathrm{~Pa} \mathrm{~s}^{-1}$ every $2.0 \mathrm{~Pa} \mathrm{~s}^{-1}$ ). Labels represent the airstreams associated with W1, W2, and W3. 
the descending W1 (omega exceeding $6 \mathrm{~Pa} \mathrm{~s}^{-1}$ ). Similarly, in a simulation of the Gudrun windstorm, Baker et al. (2014) showed that the sting jet was located in a region of weak $\theta_{w}$ gradient, where the weak positive moist static stability layer that lay between two unstable layers, was penetrated by the sting jet.

Cross section $\mathrm{EE}^{\prime}$ was taken along W3 at 0415 UTC, starting from the back to the front of the wind maximum with respect to the along-flow direction. W3 was centered at about $2 \mathrm{~km}$ in altitude (Fig. 8e). The leading part of this elongated wind maximum was characterized by ascent. Conversely, the rear part was associated with frontolysis and weak descent that was also present in cross section $\mathrm{FF}^{\prime}$ (Fig. 8f). There, the high-momentum air continued to be brought downward. Given that W3 merged with W1-W2, air with sting-jet characteristics comprised the rear part of $\mathrm{W} 3$, whereas the air in the leading part had a different origin, indicating that two airstreams comprised the single wind maximum W3.

\section{Backward trajectories}

To provide a Lagrangian perspective on the path followed by the air parcels encountered in the strongwind area, backward trajectories were computed using HYSPLIT (Stein et al. 2015) with input data from the WRF simulation and a time step of $15 \mathrm{~min}$. All trajectories were computed back to 1800 UTC 2 December and the "initialization time" of the back trajectories will be referred to as the "ending time" (considering their evolution forward in time). The trajectories were initialized from the 925-hPa wind maxima and were chosen among those that experienced the largest vertical displacement.

Air parcel trajectories that ended up in the region of W1 and W2 were computed to determine if parcels descended from midlevels of the cloud head and thus determine if these two wind maxima could be associated with the sting jet. All trajectories computed for 0130 UTC ended in W1, whereas those computed for 0230 UTC ended in W1 (black-green pair) and W2 (red-blue pair), respectively (Fig. 9). Trajectories ending at 0130 UTC in W1 originated west of the cyclone center and they followed two distinct paths until 0000 UTC 3 December. The red-black pair of trajectories had a more curved path and came from about $700 \mathrm{hPa}$. The other pair of trajectories (green-blue) had a more zonal path and came from higher levels (about $550 \mathrm{hPa}$ ) where between 1800 and 2100 UTC they resided within midtropospheric flow. At 0000 UTC 3 December, both pairs of air parcels were located within the midlevels of the bent-back front $(750 \mathrm{hPa})$ and in the next hour descended (more rapidly after
0045 UTC) to $850 \mathrm{hPa}$ (Fig. 9a). During this hour, the air parcels dried out, their relative humidity decreasing from about $90 \%$ to $60 \%-65 \%$. At the same time, the potential temperature of the green-blue trajectories experienced little change (from 292 to $296 \mathrm{~K}$ to about $293-295 \mathrm{~K}$ ), but then the potential temperature decreased and the mixing ratio increased after 0045 UTC. This behavior indicates that the air parcels experienced little cooling and moistening due to evaporation before entering the boundary layer. Air parcels that ended up in W1 and W2 at 0230 UTC originated from the lower troposphere, east of the cyclone center and followed a cyclonic path along the bent-back front while ascending to about $750 \mathrm{hPa}$. When they arrived west of the cyclone center, the air parcels started to descend. The red-blue pair needed $2.5 \mathrm{~h}$ to ascend and $2 \mathrm{~h}$ (0030-0230 UTC) to reach $925 \mathrm{hPa}$, but the black-green pair evolved much faster, ascending in about an hour, then descending in about an hour (Fig. 9b). The descent rates of these air parcels may be much higher than in previously studied sting-jet cases where air parcels needed at least $3 \mathrm{~h}$ to descend about $150 \mathrm{hPa}$ (e.g., Smart and Browning 2014; Volonté et al. 2018). Similar to the trajectories ending at 0130 UTC, the trajectories ending at 0230 UTC experienced a decrease of relative humidity and little cooling and moistening due to evaporation before entering the boundary layer.

Trajectories computed back in time to 0000 UTC 2 December (not shown) showed that air parcels ending in W1 at 0130 UTC followed the path of the cyclone that came from the central basin of the Mediterranean Sea and crossed the Šar and Rodopes Mountains (about $2700 \mathrm{~m}$ height) before reaching the bent-back front. In contrast, air parcels that ended in W1 at 0230 UTC traveled with the cyclone that came from south, over the Aegean Sea and the Black Sea, traveling with the warm conveyor belt, before arriving in the bent-back front. The different paths of the air parcels ending in the stingjet area could be a characteristic of intense cyclones which resulted from the interaction of two low pressure systems.

By measuring the length of the trajectories, some remarks can be made about their speed. For trajectories that ended at 0130 UTC, the speed of the air parcels increased considerably after 0000 UTC 3 December (Fig. 9a). For trajectories that ended at 0230 UTC, the red-blue pair traveled with a higher speed after 2100 UTC 2 December, decreased slightly between 0000 and 0100 UTC then strongly increased in speed until the end; for the black-green pair, their speed increased after 0000 UTC, slowed down around 0100 UTC and increased again after 0115 UTC (Fig. 9b). Thus, air parcels that arrived in $\mathrm{W} 1$ and $\mathrm{W} 2$ (i.e., the airstreams 

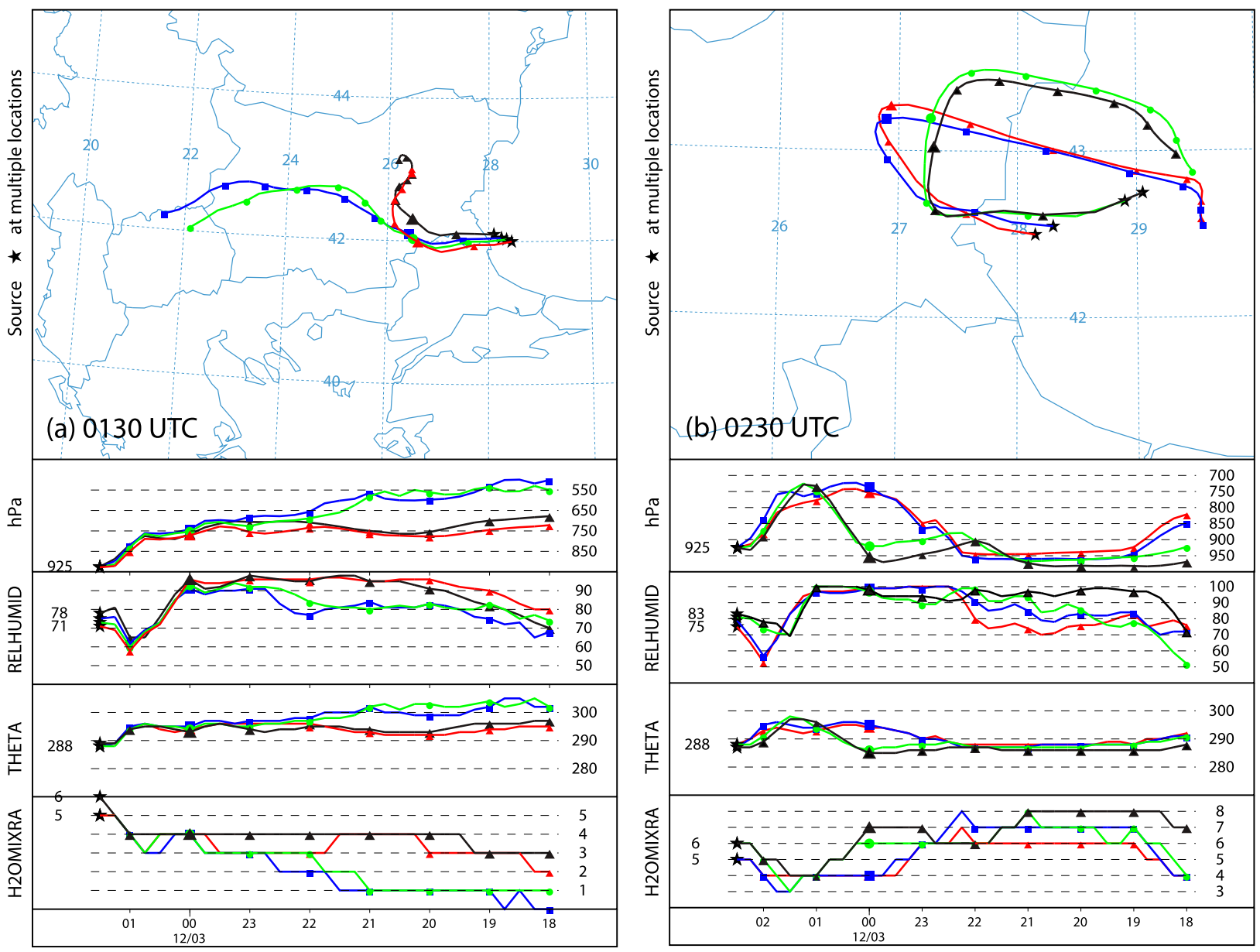

FIG. 9. Backward trajectories starting at $925 \mathrm{hPa}$ at (a) 0130 and (b) 0230 UTC 3 Dec and ending at 1800 UTC 2 Dec 2012 calculated with HYSPLIT using the WRF simulation. The time series represent sea level pressure (hPa), relative humidity with respect to water (\%), potential temperature $(\mathrm{K})$, and water vapor mixing ratio $\left(\mathrm{g} \mathrm{Kg}^{-1}\right)$. The time axis on the bottom plot is reversed.

associated with the sting jet) accelerated during the descent, with the air parcels that ended in W1 at 0230 UTC experiencing the largest acceleration. The air parcels that had a cyclonic path, ending up in W1 and W2 at 0230 UTC, experienced acceleration twice. The first acceleration happened when the air parcels were ascending (2200-0100 UTC), and the second acceleration happened when the air parcels were descending (0100-0230 UTC).

The W1 and W2 trajectories resembled sting-jet trajectories. They had the same origin and same cyclonic path as in the sting-jet case of Smart and Browning (2014) (although some of them originated west-northwest of the cyclone center as in Martínez-Alvarado et al. 2014), and they descended from the midlevels of the bent-back front to south of the cyclone center while their relative humidity decreased and their speed increased. The paths described by the air parcels that ended at 0230 UTC resembled the path followed by the lower part of the cyclonic branch of the warm conveyor belt in cyclones that form sting jets.

To determine the source or sources of the $\mathrm{W} 3$ wind maximum, two back trajectories ending at 0415 UTC into the leading part of W3 (black-green pair) and two back trajectories ending into the rear part of W3 (redblue pair) were generated (Fig. 10a). The leading part is associated with the area where W3 formed initially as a separate wind maximum at 0330 UTC (Fig. 5d), and the rear part is associated with the area where W3 merged with W1 and W2. These air parcels originated east-northeast of the cyclone center but their cyclonic paths were more northerly than those who ended in W1 and W2. Although their paths appeared similar, the evolution of their properties was different (Fig. 10a). The black-green pair, having less moisture and warmer than the red-blue pair, started descending from above $900 \mathrm{hPa}$ at 1800 UTC 2 December. During their ascent along the bent-back front after 0000 UTC, 

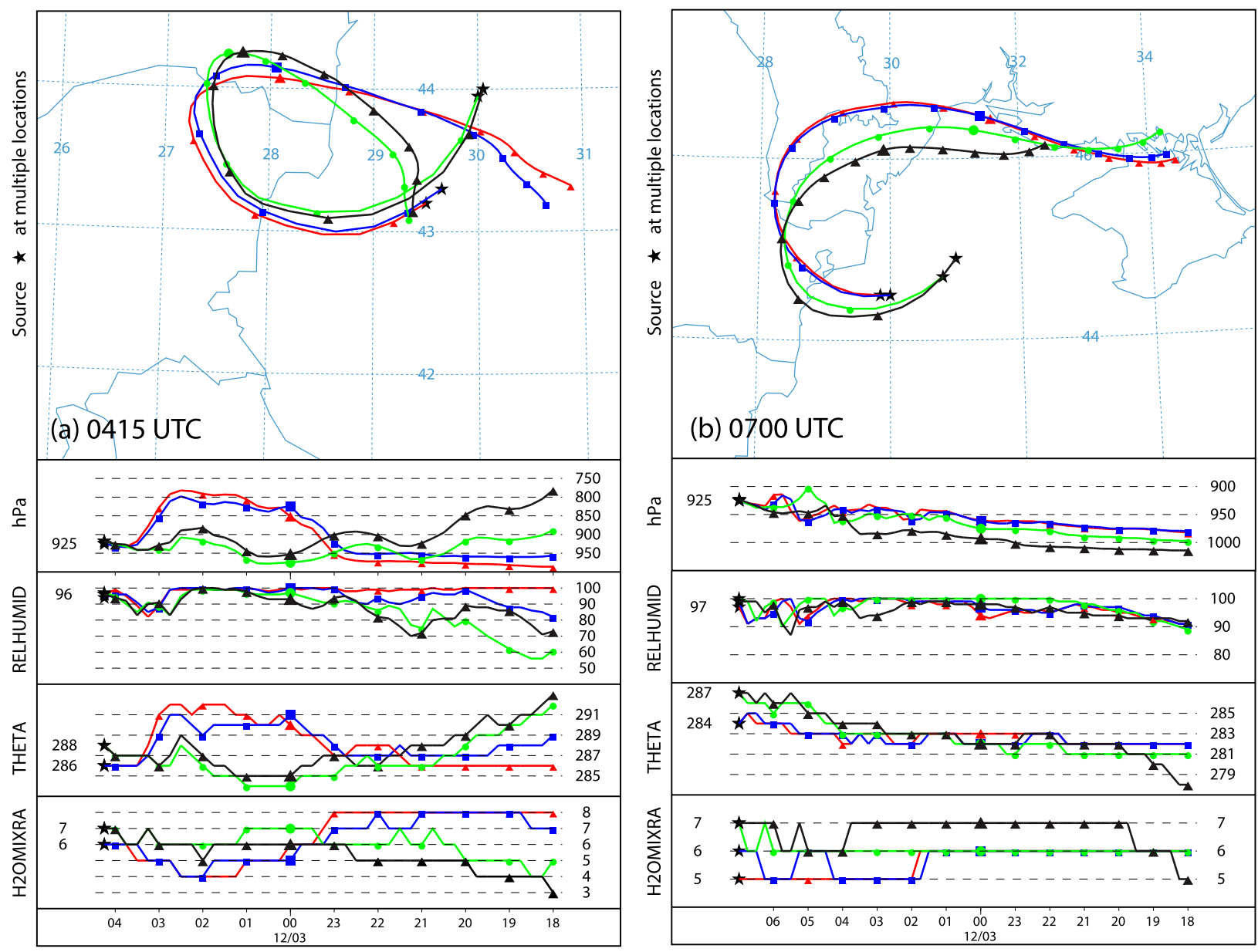

FIG. 10. As in Fig. 9, but for (a) 0415 and (b) 0700 UTC 3 Dec.

they warmed and maintained a nearly constant mixing ratio, but did not rise above $875 \mathrm{hPa}$. In contrast, the red-blue pair started rising earlier (2300 UTC), rose up to $800 \mathrm{hPa}$ along a stronger ascent region along the bent-back front, and warmed due to latent heat release. After 0230 UTC they started to descend. At this time, the moist air parcels were located in an area where frontolysis was still active and where the highmomentum air continued to be brought downward. Their relative humidity during descent decreased by just $20 \%-80 \%$. After 0200 UTC, the speed of air parcels ending in W3 began to increase, especially the speed of the black-green pair. Although all these trajectories started from the same region, the different physical processes experienced by the air parcels along their paths changed their properties and thus, they ended in different regions of the same wind maximum. Thus, W3 had two different sources, representing a transition between the sting jet (at least what remained of $\mathrm{W} 1$ and W2) acting on the rear part and the cold conveyor belt acting on the leading part.
Air parcels that ended in the wind maximum located south-southeast of the cyclone center at 0700 UTC came from the northeast and traveled just above the surface (under $900 \mathrm{hPa}$ and slightly upward), were much colder than the $\mathrm{W} 1, \mathrm{~W} 2$, and $\mathrm{W} 3$ trajectories (the potential temperature was less than $284 \mathrm{~K}$ ) and had relative humidity higher than $90 \%$ (Fig. 10b). These trajectories experienced little acceleration when traveling around the cyclone center below the bent-back front, until 0400-0500 UTC when the speed started to increase. These trajectories represent air in the cold conveyor belt.

To summarize these trajectories, air parcels that ended in the wind maxima south of the cyclone center can be associated with three different types of trajectories: 1) synoptic-scale descending trajectories (i.e., air parcels originating from the midtroposphere above $750 \mathrm{hPa}$ ending in W1 at 0130 UTC), 2) ascent-descent trajectories (i.e., air parcels coming from the northeast of the cyclone center, encircling it, and ending in W1 and W2 at 0230 UTC), and 3) low-level ascending 
trajectories (i.e., air parcels coming northeast of the cyclone center undergoing weak ascent to a height no higher than $900 \mathrm{hPa}$ and ending at 0700 UTC). The first two types of trajectories have characteristics associated with the sting jet (Martínez-Alvarado et al. 2014). However, the 0415 UTC trajectories seem to be a combination of trajectories similar to a sting jet and the cold conveyor belt, similar to the findings of Browning (2004), Smart and Browning (2014), and Slater et al. $(2015,2017)$ who argued that a single wind maximum could be composed of air parcels with a variety of previous histories (discussed in Schultz and Browning 2017). The third type of trajectory represents the cold conveyor belt. The characteristics of the ascent-descent trajectories (i.e., moist air parcels ascending northeast from the cyclone center and turning cyclonically before the descent) support the idea that the sting jet is related to the lower part of the cyclonic portion of the warm conveyor belt.

\section{Acceleration of the strong wind}

Following Slater et al. (2015, 2017), we used the horizontal momentum equation to investigate what caused the acceleration of air parcels, especially the descending air parcels that ended in W1 and W2. The form of the horizontal momentum equation is

$$
\begin{aligned}
\frac{\partial \mathbf{V}_{h}}{\partial t}= & \underbrace{-\left(\mathbf{V}_{h} \cdot \nabla_{h}\right) \mathbf{V}_{h}}_{\text {HADV }}-\underbrace{w \cdot \frac{\partial \mathbf{V}_{h}}{\partial z}}_{\text {VADV }}-\underbrace{f \mathbf{k} \times \mathbf{V}_{h}}_{F^{\mathrm{COR}}}-\underbrace{\frac{1}{\rho} \nabla p}_{F^{\mathrm{PGF}}} \\
& +F^{\mathrm{PBL}}+F^{\mathrm{DIFF}}+F^{\mathrm{CURV}}+\mathrm{RES},
\end{aligned}
$$

where $\partial \mathbf{V}_{h} / \partial t$ is the local acceleration of the horizontal wind, $w$ is the vertical velocity, $f$ is the Coriolis parameter, $\rho=\rho(x, y, z)$ is the density, and $p=p(x, y, z)$ is the pressure. The right-hand side of (3) contains eight terms: the horizontal advection of horizontal momentum (HADV), the vertical advection of the horizontal momentum (VADV), the Coriolis force $\left(F^{\mathrm{COR}}\right)$, the pressure gradient force $\left(F^{\mathrm{PGF}}\right)$, the term produced by the boundary layer parameterization scheme $\left(F^{\mathrm{PBL}}\right)$, the term resulting from explicit horizontal diffusion in the model $\left(F^{\mathrm{DIFF}}\right)$, the term that accounts for curvature of the model grid ( $F^{\mathrm{CURV}}$ ), and the residual term (RES). The residual term contains errors resulting from the time-interpolation of $\partial \mathbf{V}_{h} / \partial t$ and implicit horizontal diffusion. The $F^{\mathrm{PBL}}$ term is calculated by taking the momentum tendency from the boundary layer parameterization scheme, and includes friction and vertical diffusion. The rest of the right-hand side terms of the horizontal momentum equation are output directly from the model.
Among the terms on the right-hand side of the equation, only the along-flow pressure gradient force and the vertical advection terms produce an increase in wind speed on the equatorward side of the cyclone at any given horizontal level. The horizontal advection term helps in redistributing the momentum in the horizontal plane, the Coriolis force acts to turn the winds, and friction from the boundary layer reduces the winds. The residual term is small compared to the other terms. The contribution of $F^{\mathrm{PGF}}$ to local changes in wind speed was calculated by projecting the force onto the unit vector of the horizontal wind. To better illustrate the influence of $F^{\text {PGF }}$, both positive and negative values were plotted at $925 \mathrm{hPa}$ (Fig. 11).

The along-flow pressure gradient force accelerated the flow along the warm and the bent-back front. The largest acceleration occurred at the tip of the cloud head, upstream of the wind maximum where strong $F^{\mathrm{PGF}}$ (values of $32 \mathrm{~m} \mathrm{~s}^{-1} \mathrm{~h}^{-1}$ ) increased the wind speed from 30 to $35 \mathrm{~m} \mathrm{~s}^{-1}$ at 0045 UTC (not shown) to more than $45 \mathrm{~m} \mathrm{~s}^{-1}$ by 0130 UTC (Fig. 11a). The vertical advection term (VADV), although smaller than $F^{\text {PGF }}$, had the largest values at the tip of the cloud head, along the $\mathrm{W} 1$ and $\mathrm{W} 2$ and upstream of $\mathrm{W} 1$ and $\mathrm{W} 2$ region at 0230 UTC, in the same areas where the trajectories of $\mathrm{W} 1$ and $\mathrm{W} 2$ had passed through (Figs. 11a,b). These two terms accelerated the flow and helped in transporting the high-momentum air from midlevels down to the boundary layer until 0230 UTC. In contrast, the pressure gradient force in the southeastern part of W1 and W2 acted to decelerate the wind, thus modifying the shapes of the isotachs by weakening the most intense winds. The rest of the wind field remained unchanged and continued its movement toward the northeast. Later, this transport from above ceased. The pressure gradient force weakened but extended along the new wind maximum after 0415 UTC, thus continuing to accelerate the wind from the rear side of W3 (Figs. 11c,d). Thus, the sting jet associated with the $\mathrm{W} 1$ and $\mathrm{W} 2$ wind maxima had the largest acceleration due to $F^{\mathrm{PGF}}$, consistent with the findings of Slater et al. $(2015,2017)$. The increase in pressure-gradient force as the air parcels descend is explained by the weak gradient in geopotential height at midlevels (Fig. 2b), where the sting jet originates (i.e., red-black trajectories in Fig. 9a). As the air descends, it encounters stronger gradients around the intense cyclone center near the surface, which leads to acceleration. Also, the presence of the vertical-advection term in the frontal zone facilitated the mixing of the high-momentum air from above into the boundary layer.

For those descending, accelerated air parcels to be able to reach the surface, however, the static stability of the boundary layer needed to be near-neutral, facilitating mixing of the high-momentum air down from the free 

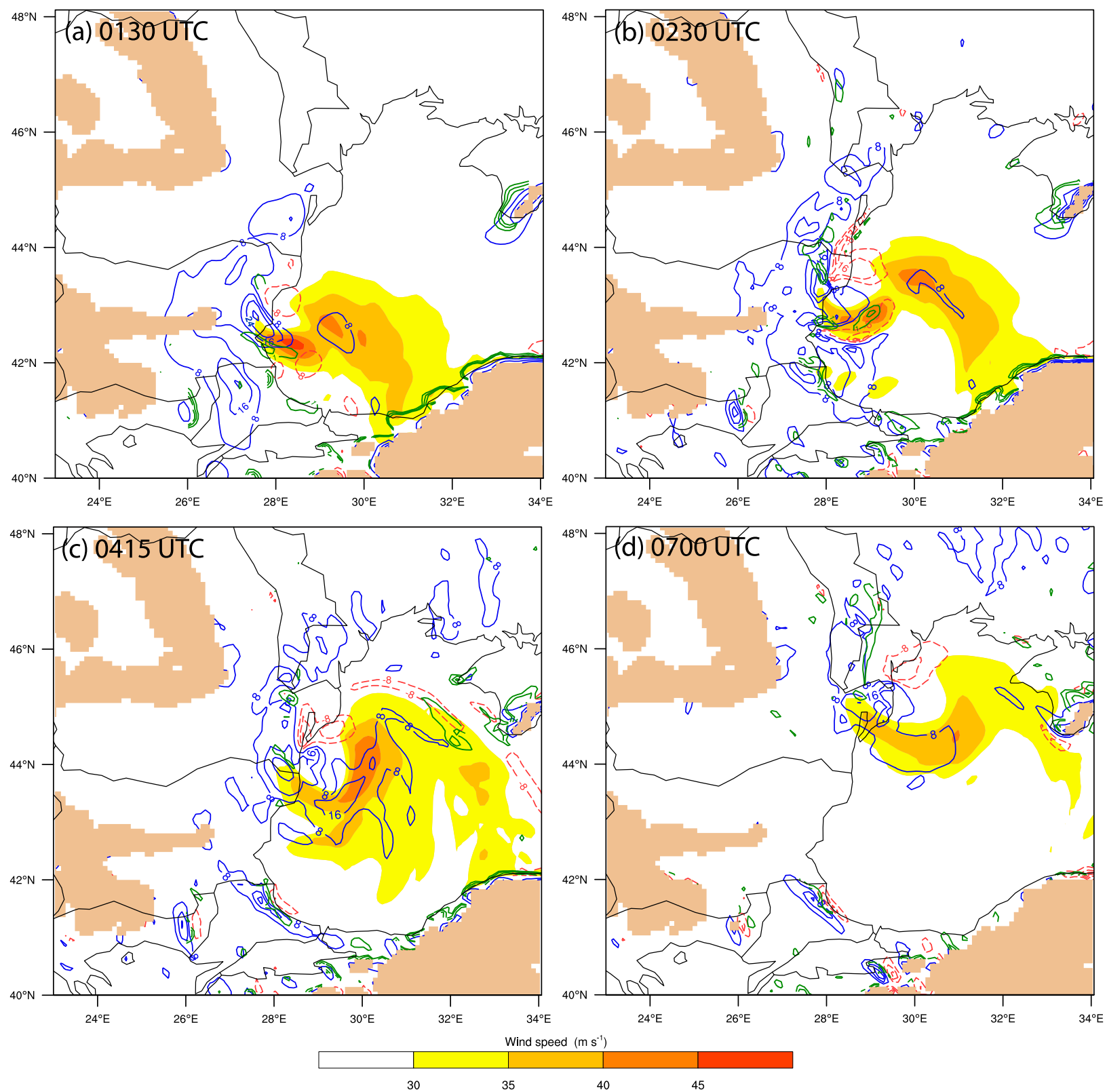

FIG. 11. Along-flow horizontal pressure gradient force (blue lines contoured at $8,16,24$, and $32 \mathrm{~m} \mathrm{~s}^{-1} \mathrm{~h}^{-1}$, red lines contoured $-32,-24$, $-16,-8 \mathrm{~m} \mathrm{~s}^{-1} \mathrm{~h}^{-1}$ ), vertical advection of the horizontal momentum (green lines contoured at 1,2 , and $4 \mathrm{~m} \mathrm{~s}^{-1} \mathrm{~h}^{-1}$ ), and horizontal wind speed at $925 \mathrm{hPa}$ (shaded according to the scale) shown for: (a) 0130, (b) 0230, (c) 0415, and (d) 0700 UTC 3 Dec. The brown shading represents areas in which the 925 -hPa surface is below ground.

atmosphere into the boundary layer (Browning and Field 2004; Schultz and Sienkiewicz 2013; Browning et al. 2015; Browning and Smart 2018). When the W1 wind maximum was forming, the 975-950-hPa layer static stability decreased and became unstable immediately behind the cold front, whereas it was near-neutral farther west of the coldfrontal boundary and near the bent-back front (Figs. 8a and 12a). The surface flux of sensible heat helped to lower the static stability later, when its values increased from
$100 \mathrm{Wm}^{-2}$ at $0230 \mathrm{UTC}$ to $200 \mathrm{Wm}^{-2}$ at $0700 \mathrm{UTC}$ (Figs. 12b-d). The W2 wind maximum was located in a weak statically stable area where the surface flux had a large influence at that time, resulting in these strong winds reaching the surface there (Figs. 8c,d and 12b). Regions of statically unstable air were present behind the cold front at 0230 UTC, and later in the area of strong winds caused by the cold conveyor belt (Figs. 12b,d). This case emphasized the important role of surface fluxes in creating the 

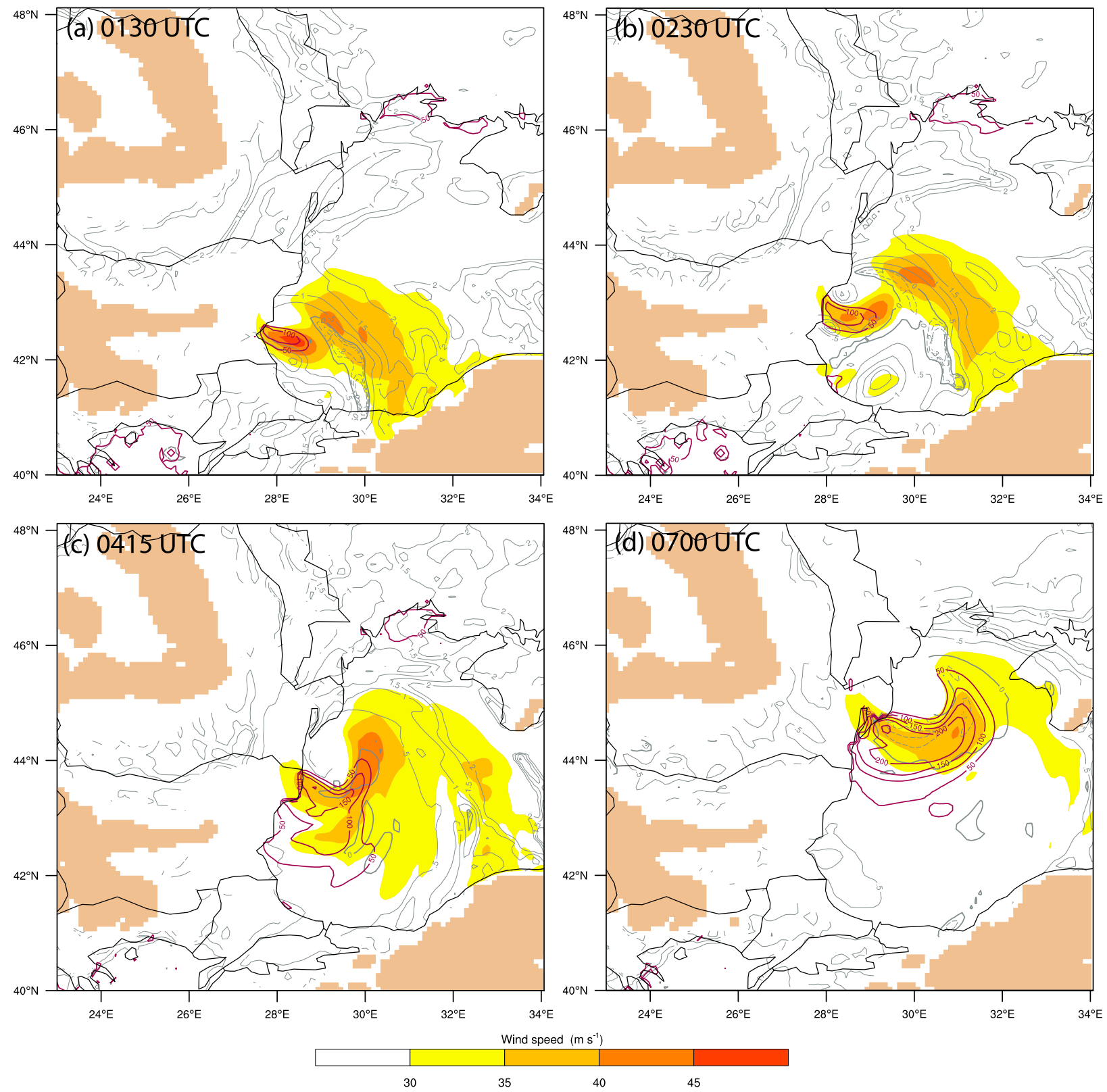

FIG. 12. Surface sensible heat flux (positive when directed into the atmosphere, magenta lines contoured at 50, 100, 150, and $200 \mathrm{~W} \mathrm{~m}^{-2}$ ), static stability measured by the potential temperature at $950 \mathrm{hPa}$ minus potential temperature at $975 \mathrm{hPa}$ (gray lines; dashed is negative $-0.3,-0.2,-0.1 \mathrm{~K}$ and solid is positive $0,0.5,1,1.5$, and $2 \mathrm{~K}$ ), horizontal wind speed at $925 \mathrm{hPa}$ (shaded according to the scale) shown for: (a) 0130, (b) 0230, (c) 0415, and (d) 0700 UTC 3 Dec. The brown shading represents areas in which the 925-hPa surface is below ground.

near-neutral conditions of the boundary layer equatorward of the cyclone center, allowing the high-momentum air associated with the sting jet to reach the surface.

\section{The role of mesoscale instabilities}

The presence and the descent of sting-jet winds have been associated with different types of instabilities (e.g.,
Gray et al. 2011; Martínez-Alvarado et al. 2014; Volonté et al. 2018). In the present study, we examine three types of instabilities (i.e., conditional instability, conditional symmetric instability, inertial instability) to determine their presence and their role in producing the high winds. First, we determine conditional instability with respect to upright convection by regions with positive values of most unstable convective available potential 
energy (MUCAPE), calculated for the parcel with maximum $\theta_{e}$ in the column (i.e., the parcel is obtained by averaging temperature and moisture over the lowest $500 \mathrm{~m}$ ). We determine inertial instability when the vertical component of absolute vorticity $(\zeta)$ is negative. We determine conditional symmetric instability when the moist potential vorticity (MPV) is negative. Specifically,

$$
\mathrm{MPV}=\frac{1}{\rho} \boldsymbol{\zeta} \cdot \nabla \theta_{\mathrm{es}},
$$

where $\rho$ is density, $\boldsymbol{\zeta}$ is the absolute vorticity, and $\theta_{e s}$ is the saturation equivalent potential temperature. Regions are defined as having only conditional symmetric instability only if inertial and conditional instabilities are absent (Schultz and Schumacher 1999). If all these three instabilities are absent, then the region is considered to be stable.

The regions in which the airstreams passed through were evaluated with respect to mesoscale atmospheric instabilities before and when the airstreams started to descend. The air parcel trajectories that ended at 0130 UTC 3 December and are associated with W1 (brown circles) started to descend at 0000 UTC from about $750 \mathrm{hPa}$ (Fig. 9a). Trajectories ending at 0230 UTC in W2 (blue circle) and W1 (pink circle) also descended from about $750 \mathrm{hPa}$, beginning their descent at 0030 and 0115 UTC, respectively (Fig. 9b). To illustrate these paths, the location of every pair of trajectories was identified on plotted maps of the three instabilities and marked with a circle. We will refer to the associated air parcels as the wind maximum where the trajectories, marked with different color circles, ended.

When they started to descend all air parcels were located in the cloud band of the bent-back front (Figs. 14a,d). Although conditional instability was present in the cold- and warm-frontal regions, W1-brown and W2blue air parcels did not pass through a conditionally unstable region prior to descent (Fig. 13). Only the W1pink air parcels would have passed through a conditionally unstable region at 0000 UTC. Before descending at 2300 UTC, the W1-brown air parcels traveled along areas weakly unstable to both conditional symmetric instability and inertial instability (not shown). These air parcels started to descend from the middle of the cloud head, from regions of stability (Figs. 14a and 15a). When they arrived at $850 \mathrm{hPa}$ at $0100 \mathrm{UTC}$, they briefly passed through regions that were drier and unstable to inertial instability (Fig. 15b). Conditional symmetric instability was also present at 850 and $925 \mathrm{hPa}$, but the saturation condition was not met (Figs. 14b,c). The paths of air parcels that arrived in
W1-brown resemble the paths of air parcels that ended in the W1 core from Fig. 8a (not shown) and, likewise, those air parcels were not in unstable regions at the time of the formation of W1.

At 0000 UTC, W1-pink air parcels were located at 950-925 hPa in a frontogenetic area with omega values greater than $-2 \mathrm{~Pa} \mathrm{~s}^{-1}$, rising up from a region that was weakly unstable to conditional symmetric instability (not shown). Similar to W1-brown, the W1-pink air parcels started to descend from a stable area, but closer to the tip of the bent-back front (Figs. $14 \mathrm{~d}$ and 15d). Although these air parcels were not located in an area unstable to inertial instability at $850 \mathrm{hPa}$, they could have passed through the upper limit of the inertial instability band located west of their positions (Fig. 15e).

In contrast, W2-blue air parcels started to descend northward of the cloud head tip, also from a stable region but traveled through areas that were weakly unstable to conditional symmetric instability at 0100 UTC (Fig. 14d). They arrived at $925 \mathrm{hPa}$ in a dry area unstable to inertial instability (Figs. $14 \mathrm{e}$ and $15 \mathrm{e}$ ). Nevertheless, the near-surface wind maximum W2 did not have a higher intensity nor last longer than W1. Inertial instability appears to be related with the latter part of the descent of W1-brown and W2-blue. Figure 15 shows that inertial instability is present in narrow bands along the bent-back front. This characteristic is consistent with the findings of Volonté et al. (2018, their Fig. 8), where inertial instability was present in narrow sloping bands, less than $100 \mathrm{hPa}$ deep.

W1-brown air parcels were characterized by omega values of 2-6 Pa s${ }^{-1}$, whereas for W1-pink and W2blue air parcels omega had larger values (i.e., 4-8 $\mathrm{Pa} \mathrm{s}^{-1}$ ) (Fig. 14). Coupled with the cold-air advection in the lower troposphere and the frontolytic circulations along the end of the bent-back front, descent occurred in this area. Because W1-brown and W2-blue air parcels started to descend farther northwest of the cloud head tip, along the bent-back front, their descent was initially associated with synoptic-scale processes for descent (e.g., cold-air advection) and later with mesoscale frontolysis. The descent of W1-pink air parcels appears to be related only with the frontolytic circulation due to their starting position of descent.

Tracing these W1 and W2 parcels from 0230 UTC backward, they appear to have originated at the base of the warm conveyor belt (Fig. 9b). The wind vectors showed the strong northward circulation of the warm conveyor belt that turned to the west and split into the cyclonic and anticyclonic branches, respectively 


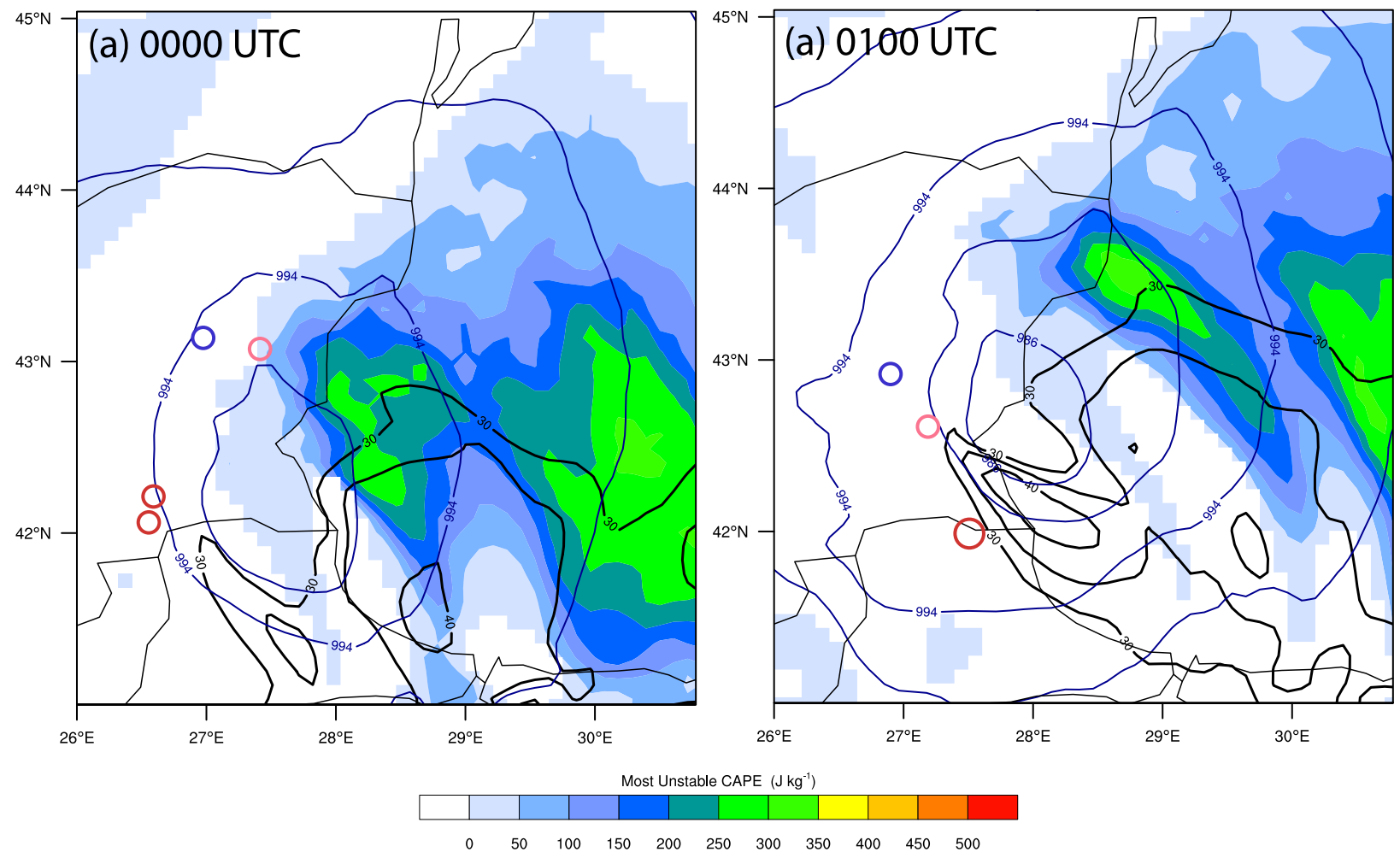

FIG. 13. Most unstable CAPE ( $\mathrm{J} \mathrm{kg}^{-1}$, shaded according to the scale), mean sea level pressure (blue lines contoured every $\left.4 \mathrm{hPa}\right)$, and horizontal wind speed at $925 \mathrm{hPa}$ (bold black lines contoured from 30 to $50 \mathrm{~m} \mathrm{~s}^{-1}$ every $5 \mathrm{~m} \mathrm{~s}^{-1}$ ) shown for: (a) 0000 and (b) 0100 UTC 3 Dec. The circles represent the location of air parcel trajectories at each time. The brown circles represent the four trajectories ending in W1 at 0130 UTC; for 0100 UTC, a larger circle was made due to the small distance between the location of trajectories. The pink and blue circles represent the two trajectories ending in W1 (black-green pair) and W2 (red-blue pair), respectively at 0230 UTC.

(Fig. 15). This structure of the cyclonic branch of the warm conveyor belt resembles the structure of the warm conveyor belt in an intense Shapiro-Keyser extratropical cyclone depicted by Browning and Roberts (1994, their Fig. 9).

After evaluating the stability of the parcels with respect to the various types of instabilities and frontal circulation, we concluded that:

(i) conditional symmetric instability was sometimes present during ascent before the sting-jet formation;

(ii) inertial instability was present in the last part of the sting jet's descent when the sting jet entered into the boundary layer;

(iii) most air parcel trajectories indicated that the sting jet originated from the lower part of the cyclonic branch of the warm conveyor belt; and

(iv) the descent of the sting jet can be associated with the synoptic-scale dynamics at the beginning and with the mesoscale secondary circulation associated with the frontolysis later.

Our results are more consistent with Smart and Browning (2014) who did not find evidence of instabilities in their case study of a sting-jet cyclone and less consistent with Volonté et al. (2018) who found conditional symmetric instability, symmetric instability, inertial instability, and conditional instability present at various times during descent. On the other hand, these results are in contrast to previous studies such as Gray et al. (2011) who found conditional symmetric instability present at the time of descent. As the number of sting-jet cases in the literature grow, we hope that further light will be shed on the relative importance of these various instabilities to the strong winds in cyclones.

\section{Conclusions}

On 2-3 December 2012, a rapidly developing Mediterranean cyclone produced damaging winds that affected the Black Sea area, including southeastern Romania. The cyclone followed the Shapiro-Keyser model and developed strong winds equatorward of the cyclone center. The cyclone evolution was simulated using the mesoscale model WRF and the results showed that the strong winds were associated with two different airstreams: 

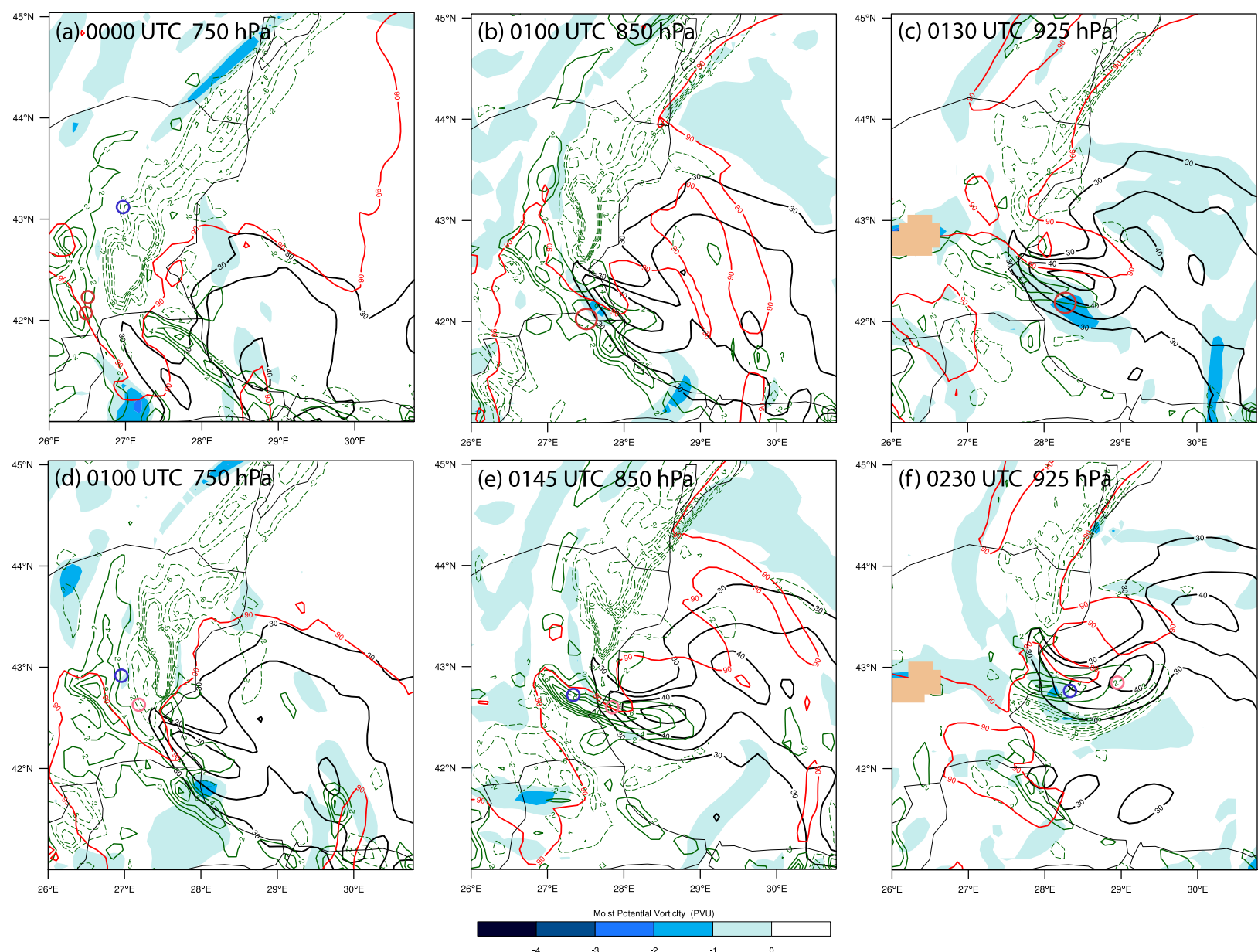

FIG. 14. Moist potential vorticity (PVU, shaded according to the scale), omega (green dashed lines representing ascent contoured for $-10.0,-8.0,-6.0,-4.0,-2.0 \mathrm{~Pa} \mathrm{~s}^{-1}$, and green solid lines representing descent contoured for 2.0, 4.0, 6.0, 8.0, 10.0 Pa s ${ }^{-1}$ ), and relative humidity (red line $>90 \%$ ) at (a),(d) $750 \mathrm{hPa}$; (b),(e) $850 \mathrm{hPa}$; and (c),(f) $925 \mathrm{hPa}$; horizontal wind speed at $925 \mathrm{hPa}$ (black lines contoured from 30 to $50 \mathrm{~m} \mathrm{~s}^{-1}$ every $5 \mathrm{~m} \mathrm{~s}^{-1}$ ) shown for: (a) 0000, (b),(d) 0100, (c) 0130, (e) 0145, and (f) 0230 UTC 3 Dec. The notation for the circles is described in Fig. 13. The brown shading represents areas in which the 925-hPa surface is below ground.

(i) a descending airstream originating from the midtropospheric cloud head, whose relative humidity decreased as it descended into the warm side of the bent-back front and which was accelerated before entering the boundary layer; this airstream is a sting jet;

(ii) an airstream originating northeast of the cyclone center that traveled at low levels along and on the cold side of the bent-back front; this airstream is the cold conveyor belt.

In the model simulation, the strongest near-surface winds associated with the sting jet (more than $45 \mathrm{~m} \mathrm{~s}^{-1}$ ) occurred at 0130 UTC 3 December and lasted $2-4 \mathrm{~h}$. When intense winds were due to the sting jet, two near-surface wind maxima were identified, labeled $\mathrm{W} 1$ and $\mathrm{W} 2$. W1 was the main wind maximum with a lifetime of about $4 \mathrm{~h}$. W2 was less intense and formed behind W1, lasting almost $2 \mathrm{~h}$. Both wind maxima were associated with airstreams that descended from $750 \mathrm{hPa}$. After $0500 \mathrm{UTC}$, before the bent-back front wrapped around the cyclone center, the winds equatorward of the cyclone center were produced only by the cold conveyor belt. The winds caused by the cold conveyor belt lasted for more than 6-8 $\mathrm{h}$ with speeds up to $40 \mathrm{~m} \mathrm{~s}^{-1}$. In between, a transition period took place when the strongest winds were due to both sting jet and cold conveyor belt. This transition period was associated with the W3 wind maximum and lasted about $2 \mathrm{~h}$.

The largest acceleration of the sting jet occurred when the airstream encountered the strong horizontal pressure gradients. The vertical advection contributed to the downward transfer of high-momentum air through the boundary layer to the surface. The surface heat fluxes acted in reducing boundary layer stability equatorward of the cyclone center so that the 

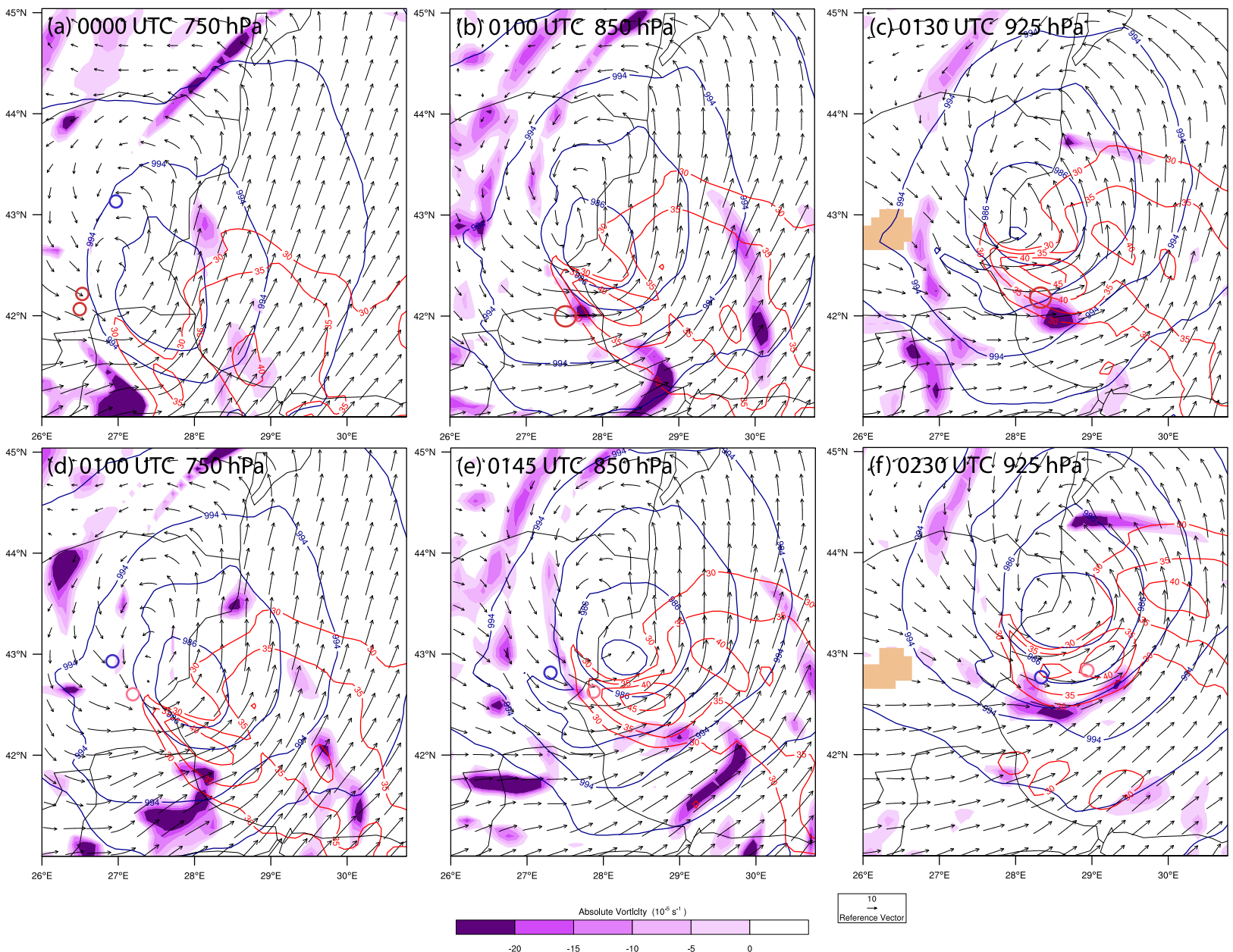

FIG. 15. Absolute vorticity $\left(10^{-5} \mathrm{~s}^{-1}\right.$, shaded according to the scale) and horizontal wind vectors (arrows) at (a),(d) $750 \mathrm{hPa}$; (b),(e) $850 \mathrm{hPa}$; and (c),(f) $925 \mathrm{hPa}$, mean sea level pressure (blue lines contoured every $4 \mathrm{hPa}$ ) and horizontal wind speed at $925 \mathrm{hPa}$ (red lines contoured from 30 to $50 \mathrm{~m} \mathrm{~s}^{-1}$ every $5 \mathrm{~m} \mathrm{~s}^{-1}$ ) shown for (a) 0000; (b),(d) 0100; (c) 0130; (e) 0145; and (f) 0230 UTC 3 Dec. The notation for the circles is described in Fig. 13. The brown shading represents areas in which the $925-\mathrm{hPa}$ surface is below ground.

high-momentum winds reach the surface. The nearneutral stability of the boundary layer was needed for the sting jet to descend to the surface and, thus to produce high-risk hazards. Mesoscale instabilities occurred before the sting jet formed when the air parcels ascended and later when the air parcels entered into the boundary layer. A small area unstable to conditional symmetric instability and inertial instability near the area from where W2 descended did not appear to have an effect on W2 because W2 was neither more intense nor lasted longer than W1, different from other previous studies where instability was present (e.g., Gray et al. 2011; MartínezAlvarado et al. 2011). Further investigation on other sting-jet cases is needed to establish the importance of mesoscale instabilities in sting-jet generation from a global perspective. The sting jet formed in an environment characterized by synoptic-scale and mesoscale descent at the frontolytic tip of the bentback front where the isentropes become diffluent.

To our knowledge, this case exhibited the first documented sting jet in a Mediterranean cyclone. The path of the cyclone over the Black Sea at the same time as the strongest winds formed was fortunate because the sting jet occurred over the sea, affecting land at the Bulgarian shoreline only for a half an hour. The strong winds that affected southeastern Romania were caused by the cold conveyor belt, consistent with wind gusts recorded by the weather stations. Fortunately, the resultant damages were considerably less than in other western European windstorms.

The case analyzed in this article had similarities and differences compared to sting jets associated with extratropical cyclones that develop over the Atlantic Ocean: 
1) The physical processes involved in its generation were the same as in other marine cases studied by Schultz and Sienkiewicz (2013) and Slater et al. (2015, 2017).

2) The sting jet originated from the midtropospheric cloud head, from the lower part of the cyclonic branch of the warm conveyor belt and descended, accelerating, close to the tip of the bent-back front.

3) The sting jet descended more rapidly (i.e., $175 \mathrm{hPa}$ in less than an hour) but had a shorter lifetime (i.e., $2-4 \mathrm{~h}$ ) compared to other cases over the North Atlantic Ocean.

4) The paths followed by the air parcels that ended in the sting-jet area were consistent with those from other demonstrated sting-jet windstorms (e.g., Martínez-Alvarado et al. 2014, their Figs. 5d,g).

5) The Mediterranean cyclone quickly underwent all phases of evolution as in the conceptual model presented by Clark et al. (2005), with the sting jet appearing at the tip of the bent-back front, ahead of cold conveyor belt.

The features of the wind field described in the above sections showed that the high-speed winds had more than one source and established their location and duration. Knowing the approximate intensity and duration of such winds-and especially their location-could represent a big advantage in operational forecasting where the identification of such weather phenomena is essential to a good forecast.

Acknowledgments. We thank the Romanian National Meteorological Administration (RNMA) for providing satellite images, Medgidia S-band radar products, and observational data for this study. We thank the two anonymous reviewers and Editor Ron McTaggartCowan for their comments that helped improve the manuscript. The authors gratefully acknowledge the NOAA/Air Resources Laboratory (ARL) for the provision of the HYSPLIT transport and dispersion model and/or READY website (http://www.ready.noaa.gov) used in this publication. Brâncuş was partially funded by RNMA and by the Doctoral School of Physics, University of Bucharest. Partial funding for Schultz comes from the U.K. Natural Environment Research Council to the University of Manchester, Grants NE/I005234/1 and NE/N003918/1. Antonescu was partially funded from Romanian STAR Program Ctr. 162/20.07.2017b and from the Romanian National Core Program Contract. 18N/2019.

\section{REFERENCES}

Baker, L. H., 2009: Sting jets in severe northern European wind storms. Weather, 64, 143-148, https://doi.org/10.1002/ wea.397.
_ S. L. Gray, and P. A. Clark, 2014: Idealised simulations of sting-jet cyclones. Quart. J. Roy. Meteor. Soc., 140, 96-110, https://doi.org/10.1002/qj.2131.

Browning, K. A., 1990: Organization of clouds and precipitation in extratropical cyclones. Extratropical Cyclones: The Erik Palmén Memorial Volume, C. W. Newton and E. O. Holopainen, Eds., Amer. Meteor. Soc., 129-153.

_ 2004: The sting at the end of the tail: Damaging winds associated with extratropical cyclones. Quart. J. Roy. Meteor. Soc., 130, 375-399, https://doi.org/10.1256/qj.02.143.

— Quart. J. Roy. Meteor. Soc., 120, 1535-1557, https://doi.org/ 10.1002/qj.49712052006.

— , and M. Field, 2004: Evidence from Meteosat imagery of the interaction of sting jets with the boundary layer. Meteor. Appl., 11, 277-289, https://doi.org/10.1017/S1350482704001379.

— , and D. J. Smart, 2018: Invigoration of convection by an overrunning diabatically modified cloud-top layer. Quart. J. Roy. Meteor. Soc., 144, 142-155, https://doi.org/10.1002/qj.3190.

,,-- M. R. Clark, and A. Illingworth, 2015: The role of evaporative showers in the transfer of the sting-jet momentum to the surface. Quart. J. Roy. Meteor. Soc., 141, 2956-2971, https://doi.org/10.1002/qj.2581.

Carlson, T. N., 1980: Airflow through midlatitude cyclones and the comma cloud pattern. Mon. Wea. Rev., 108, 1498-1509, https:// doi.org/10.1175/1520-0493(1980)108<1498:ATMCAT>2.0.CO;2.

Chen, F., and J. Dudhia, 2001: Coupling an advanced land surface-hydrology model with the Penn State-NCAR MM5 modeling system. Part I: Model implementation and sensitivity. Mon. Wea. Rev., 129, 569-585, https://doi.org/10.1175/ 1520-0493(2001)129<0569:CAALSH > 2.0.CO;2.

Clark, P. A., and S. L. Gray, 2018: Sting jets in extratropical cyclones: A review. Quart. J. Roy. Meteor. Soc., 144, 943-969, https://doi.org/10.1002/qj.3267.

— K. A. Browning, and C. Wang, 2005: The sting at the end of the tail: Model diagnostics of fine-scale three-dimensional structure of the cloud head. Quart. J. Roy. Meteor. Soc., 131, 2263-2292, https://doi.org/10.1256/qj.04.36.

Coronel, B., D. Ricard, G. Rivière, and P. Arbogast, 2016: Coldconveyor-belt jet, sting jet and slantwise circulations in idealized simulations of extratropical cyclones. Quart. J. Roy. Meteor. Soc., 142, 1781-1796, https://doi.org/10.1002/qj.2775.

Dudhia, J., 1989: Numerical study of convection observed during the Winter Monsoon Experiment using a mesoscale two-dimensional model. J. Atmos. Sci., 46, 3077-3107, https://doi.org/10.1175/15200469(1989)046<3077:NSOCOD>2.0.CO;2.

Ek, M. B., K. E. Mitchell, Y. Lin, E. Rogers, P. Grunmann, V. Koren, G. Gayno, and J. D. Tarpley, 2003: Implementation of Noah land surface model advances in the National Centers for Environmental Prediction operational mesoscale Eta model. J. Geophys. Res., 108, 8851, https://doi.org/10.1029/ 2002JD003296.

Gray, S. L., O. Martínez-Alvarado, L. Baker, and P. A. Clark, 2011: Conditional symmetric instability in sting-jet storms. Quart. J. Roy. Meteor. Soc., 137, 1482-1500, https://doi.org/10.1002/qj.859.

Harrold, T. W., 1973: Mechanisms influencing the distribution of precipitation within baroclinic disturbances. Quart. J. Roy. Meteor. Soc., 99, 232-251, https://doi.org/10.1002/qj.49709942003.

Hewson, T. D., and U. Neu, 2015: Cyclones, windstorms and the IMILAST project. Tellus, 67A, 27128, https://doi.org/10.3402/ tellusa.v67.27128.

Hong, S.-Y., Y. Noh, and J. Dudhia, 2006: A new vertical diffusion package with an explicit treatment of entrainment 
processes. Mon. Wea. Rev., 134, 2318-2341, https://doi.org/ 10.1175/MWR3199.1.

Kain, J. S., 2004: The Kain-Fritch convective parameterization: An update. J. Appl. Meteor., 43, 170-181, https://doi.org/10.1175/ 1520-0450(2004)043<0170:TKCPAU > 2.0.CO;2.

—, and J. M. Fritsch, 1990: A one-dimensional entraining/detraining plume model and its application in convective parameterization. J. Atmos. Sci., 47, 2784-2802, https://doi.org/ 10.1175/1520-0469(1990)047<2784:AODEPM>2.0.CO;2.

Knox, J. A., J. D. Frye, J. D. Durkee, and C. M. Fuhrmann, 2011: Non-convective high winds associated with extratropical cyclones. Geogr. Compass, 5, 63-89, https://doi.org/10.1111/ j.1749-8198.2010.00395.x.

Martínez-Alvarado, O., S. L. Gray, P. A. Clark, and L. H. Baker, 2011: Objective detection of sting jets in low-resolution datasets. Meteor. Appl., 17, 340-354, https://doi.org/10.1002/met.297.

_ , L. H. Baker, S. L. Gray, J. Methven, and R. S. Plant, 2014: Distinguishing the cold conveyor belt and sting jet airstreams in an intense extratropical cyclone. Mon. Wea. Rev., 142, 25712595, https://doi.org/10.1175/MWR-D-13-00348.1.

Meteoalarm, 2013: Immediate warnings of dangerous and extreme weather across all of Europe on Internet. Meteoalarm, 24 pp., http://bibliotheek.knmi.nl/weerbrochures/meteoalarm_eu.pdf.

Mlawer, E. J., S. J. Taubman, P. D. Brown, M. J. Iacono, and S. A. Clough, 1997: Radiative transfer for inhomogeneous atmosphere: RRTM, a validated correlated-k model for the longwave. J. Geophys. Res., 102, 16663-16682, https://doi.org/ 10.1029/97JD00237.

Nuclearelectrica, 2012: Oprirea Unităţii 1 a Centralei Nucleare Electrice Cernavodă (The stopping Unit 1 of the Cernavodă Nuclear Power Plant). Nuclearelectrica, 3 December, accessed 9 June 2018, http://www.nuclearelectrica.ro/blog/2012/ 12/03/oprirea-unitatii-1-cne-cernavoda/.

Observator de Constanţa, 2012: Furtuna a provocat pagube de 2.000 .000 de lei la şcoli (The storm caused damage of 2,000,000 lei to schools). Observator de Constanţa, 6 December, accessed 9 June 2018, http://observator.ro/furtuna-a-provocat-pagube-de2-000-000-de-lei-la-scoli-177083.html.

Parton, G. A., G. Vaughan, E. G. Norton, K. A. Browning, and P. A. Clark, 2009: Wind profiler observations of a sting jet. Quart. J. Roy. Meteor. Soc., 135, 663-680, https://doi.org/10.1002/qj.398.

—, A. Dore, and G. Vaughan, 2010: A climatology of midtropospheric strong wind events as observed by the MST radar, Aberystwyth. Meteor. Appl., 17, 340-354, https://doi.org/ 10.1002/met.203.

Petterssen, S., 1936: Contribution to the theory of frontogenesis. Geofys. Publ., 11 (6), 1-27.

Pirvoiu, C., 2012: Situaţie critică, luni dimineaţa, în sistemul energetic din cauza vântului puternic: Unitatea 1 de la Cernavodă a fost oprită, zeci de localităţi au rămas fără curent (Critical situation Monday morning in the power system because of the strong wind: Cernavodă unit 1 was stopped, dozens of localities were left without power). HotNews.ro, 3 December, accessed 9 June 2018, https://economie.hotnews.ro/stiri-energie-13735374-situatiecritica-sistemul-energetic-din-cauza-vantului-puternic-unitatea-1-cernavoda-fost-oprita-eoliene-defectat-zeci-localitati-ramas-fara-curent.htm.

Sanders, F., and J. R. Gyakum, 1980: Synoptic-dynamic climatology of the "bomb." Mon. Wea. Rev., 108, 1589-1606, https://doi.org/ 10.1175/1520-0493(1980)108<1589:SDCOT>2.0.CO;2.

Schär, C., and H. Wernli, 1993: Structure and evolution of an isolated semi-geostrophic cyclone. Quart. J. Roy. Meteor. Soc., 119, 57-90, https://doi.org/10.1002/qj.49711950904.
Schultz, D. M., 2001: Reexamining the cold conveyor belt. Mon. Wea. Rev., 129, 2205-2225, https://doi.org/10.1175/ 1520-0493(2001)129<2205:RTCCB > 2.0.CO;2.

—- and P. N. Schumacher, 1999: The use and misuse of conditional symmetric instability. Mon. Wea. Rev., 127, 2709-2732, https://doi.org/10.1175/1520-0493(1999)127<2709: TUAMOC $>2$ 2.0.CO;2; Corrigendum, 128, 1573, https://doi.org/ 10.1175/1520-0493(1999)127<1573:CORRIG > 2.0.CO;2.

—_, and J. M. Sienkiewicz, 2013: Using frontogenesis to identify sting jets in extratropical cyclones. Wea. Forecasting, 28, 603613, https://doi.org/10.1175/WAF-D-12-00126.1.

— and K. A. Browning, 2017: What is a sting jet? Weather, 72, 63-66, https://doi.org/10.1002/wea.2795.

—, D. Keyser, and L. F. Bosart, 1998: The effect of large-scale flow on low-level frontal structure and evolution in mid-latitude cyclones. Mon. Wea. Rev., 126, 1767-1791, https://doi.org/10.1175/ 1520-0493(1998)126<1767:TEOLSF $>2.0 . C O ; 2$.

Shapiro, M. A., and D. Keyser, 1990: Fronts, jet streams and the tropopause. Extratropical Cyclones: The Erik Palmén Memorial Volume, C. W. Newton and E. O. Holopainen, Eds., Amer. Meteor. Soc., 167-191.

Skamarock, W. C., and Coauthors, 2008: A description of the Advanced Research WRF version 3. NCAR Tech. Note NCAR/ TN-475+STR, 113 pp., https://doi.org/10.5065/D68S4MVH.

Slater, T. P., D. M. Schultz, and G. Vaughan, 2015: Acceleration of near-surface strong winds in a dry, idealized extratropical cyclone. Quart. J. Roy. Meteor. Soc., 141, 1004-1016, https:// doi.org/10.1002/qj.2417.

,$- \ldots$, and -2017 : Near-surface strong winds in a marine extratropical cyclone: Acceleration of the winds and the importance of surface fluxes. Quart. J. Roy. Meteor. Soc., 143, 321-332, https://doi.org/10.1002/qj.2924.

Smart, D. J., and K. A. Browning, 2014: Attribution of strong winds to a cold conveyor belt and sting jet. Quart. J. Roy. Meteor. Soc., 140, 595-610, https://doi.org/10.1002/qj.2162.

Stein, A. F., R. R. Draxler, G. D. Rolph, B. J. B. Stunder, M. D. Cohen, and F. Ngan, 2015: NOAA's HYSPLIT Atmospheric Transport and Dispersion Modeling System. Bull. Amer. Meteor. Soc., 96, 2059-2077, https://doi.org/10.1175/ BAMS-D-14-00110.1.

Stepek, A., I. L. Wijinat, G. van der Schrier, E. J. M. van der Besselaar, and A. M. G. Klein Tank, 2012: Severe wind gust thresholds for Meteoalarm derived from uniform return periods in ECA\&D. Nat. Hazards Earth Syst. Sci., 12,1969-1981, https://doi.org/10.5194/nhess-12-1969-2012.

Takayabu, I., 1986: Roles of the horizontal advection on the formation of surface fronts and on the occlusion of a cyclone developing in the baroclinic westerly jet. J. Meteor. Soc. Japan, 64, 329-345, https://doi.org/10.2151/jmsj1965. 64.3_329.

Thompson, G., P. R. Field, R. M. Rasmussen, and W. D. Hall, 2008: Explicit forecasts of winter precipitation using an improved bulk microphysics scheme. Part II: Implementation of a new snow parameterization. Mon. Wea. Rev., 136, 5095-5115, https://doi.org/10.1175/2008MWR2387.1.

Vaughan, G., and Coauthors, 2015: Cloud banding and winds in intense European cyclones: Results from the DIAMET project. Bull. Amer. Meteor. Soc., 96, 249-265, https://doi.org/ 10.1175/BAMS-D-13-00238.1.

Volonté, A., P. A. Clark, and S. Gray, 2018: The role of mesoscale instabilities in the sting-jet dynamics of windstorm Tini. Quart. J. Roy. Meteor. Soc., 144, 877-899, https:// doi.org/10.1002/qj.3264. 